\title{
La génesis del derecho administrativo: ¿fenómeno y derecho de la administración romana?
}

\author{
Nicolás Cabezas ${ }^{1}$ Y Daniel Mayorga ${ }^{2}$
}

\section{RESUMEN}

Este trabajo tiene por objeto analizar las diversas posturas jurídicas existentes acerca del nacimiento del derecho administrativo, integrando críticas a cada una de ellas y planteando una postura respecto de sus fundaciones en el derecho público romano. Por medio del estudio de los componentes de esta disciplina jurídica, se busca proponer una tesis centrada en las normas que regulan la administración pública en Roma, cuya influencia en los sistemas de derecho administrativo contemporáneo es usualmente ignorada en los puntos de partida y desarrollo de este derecho.

Palabras clave: Derecho público romano, Derecho administrativo, Servicio público, Ciencia de la policía, Cameralística, Revolución francesa.

1 Estudiante de terecer año de Derecho y monitor asistente del Departamento de Derecho Administrativo, Universidad Externado de Colombia, Bogotá, Colombia. Correo-e: nicolas.cabezas@est.uexternado.edu.co. Fecha de recepción: 28 de agosto de 2016. Fecha de modificación: 15 de septiembre de 2016. Fecha de aceptación: 28 de septiembre de 2016. Para citar el artículo: CABEZAS, N. y MAYORGA, D. "La génesis del derecho administrativo: fenómeno y derecho de la administración romana", Revista digital de Derecho Administrativo, n. ${ }^{\circ}$ 16, segundo semestre, Universidad Externado de Colombia, 2016, pp. 297-335. DOI: http://dx.doi.org/10.18601/21452946.n16.14.

2 Estudiante de tercer año de Derecho y monitor asistente del Departamento de Derecho Administrativo, Universidad Externado de Colombia, Bogotá, Colombia. Correo-e: daniel. mayorga01@est.uexternado.edu.co 


\title{
Genesis of Administrative Law: Phenomenon and Law of the Roman Administration?
}

\begin{abstract}
This work aims to study the different legal positions on the origins of Administrative Law, by challenging each of the theories traditionally used, to explain its emergence and argument in favor of its Public Roman Law foundations. Through the analysis of the elements of this legal discipline, the present article seeks to provide an alternative theory. This idea will emerge from the influence that the regulations pertaining to the Roman Public Administration has had in the development of contemporary Administrative Law; an issue largely ignored by some scholars.

Keywords: Public Law, Administrative Law, Roman Law, Roman Administrative Law, Public Service, Police Science, Cameralist, French Revolution.
\end{abstract}

\section{INTRODUCCIÓN}

A lo largo de los años se ha ido estructurando un concepto cada vez más sólido y coherente del derecho administrativo, y junto a él han surgido multiplicidad de teorías que buscan definirlo, nutrirlo y expandirlo ${ }^{3}$. Pero al propio tiempo, para la estructuración coherente de dichas teorías siempre se ha hecho necesario replantear las ya consolidadas ${ }^{4}$. Vemos ahora la necesidad de analizar y replantear aquella posición que reconoce la existencia de un derecho adminis-

3 Son de conocimiento generalizado en nuestra ciencia las varias teorías y posturas que han ayudado a la construcción dogmática ${ }_{i}$ a manera de ejemplo cabe recordar los conceptos de buena gobernancia aportados por la cameralística y la ciencia de la policía en general, y a su vez aquellos que la Revolución francesa engendró, como el principio de legalidad, o los aportes posteriores sobre las prerrogativas públicas - HAURIOU- y también sobre el servicio público -GASTON JèZE-, concepto que se analiza más adelante. El presente estudio, sin embargo, se concentra en aquellos lineamientos generales y trascendentales que pueden ser diferenciados a través del tiempo como un elemento esencial del derecho administrativo.

4 "La ciencia de la administración pública es un escenario de actividad creativa donde se produce y se reproduce el conocimiento, una institución social dedicada al progreso del ser humano. Dentro de esta ciencia, la teoría administrativa del Estado constituye una fórmula expositiva del pensamiento científico que explica sencillamente la complejidad estatal, que ensambla elementos dispersos, que ofrece sentido a lo antes incomprensible, y que hace imperativo el uso del rigor, el argumento y la evidencia": OMAR GUERRERO OrozCO, Teoría administrativa del Estado, México D.F.: Oxford University Press, 2000, p. 25. 
trativo única y exclusivamente luego de la Revolución francesa, para así poder entrar a estudiar, con fundamento en teorías teleológicas, el derecho romano que rigió por tanto tiempo; que estructuró y nutrió, no solo al derecho privado, sino también al derecho público; e incluso, que ayudó a la consolidación de un cuerpo normativo para la administración y de la administración para la época ${ }^{5-6}$.

En la búsqueda de un derecho más coherente y acorde a las necesidades de cada pueblo, se hace necesaria la estructuración de un sistema de derecho que responda a las diversas temáticas requeridas, y aunque no reconozcamos de pleno derecho la existencia de una disciplina jurídica individualizada y definida de derecho administrativo, sí debemos reconocer de facto la presencia de un cuerpo normativo organizado y cuantioso que regula todas las materias relacionadas con lo que hoy llamamos "la administración". Pues, al igual que sucedió en Inglaterra, lugar donde se negaba la existencia de una disciplina especial de derecho administrativo ${ }^{7}, y$ donde se tuvo que admitir posterior-

Para la época romana aún no se reconoce un ente llamado "administración", sin embargo sí se cuenta con una estructura pública amplia encargada de la prestación de ciertos servicios y de la gestión de intereses públicos. Incluso el término se usaba corrientemente en la antigua Roma dentro de los asuntos de gobierno. La evidencia más prístina que se conoce se debe a Sexto Julio Frontino, un funcionario romano que tuvo a su cargo la gestión del agua potable de la ciudad. En un documento donde describe sus labores, que se remonta al año 70 d.C., Frontino explica estar desempeñando una función delegada por el emperador, cuyo objeto era la administración (administratum) de los acueductos de Roma. Vid. SeXto J. Frontino, Les aqueducs de la Ville de Roma, París: Les Belles Lettres, 1944, p. 1.

6 Debe resaltarse que en la doctrina romanista actual se estudian los conceptos de "fisco" y "erario" como conceptos que representaban una entidad económica y jurídica distinta de las cuestiones propias del príncipe (en épocas posteriores a la República), en cuanto se sustraía ese patrimonio de su libre disponibilidad y se vinculaba a fines determinados objetivamente exigidos por el pueblo. De esta manera se llegó a concebir como si fuese él mismo un sujeto de derechos y relaciones, lo cual se sustenta en afirmaciones del propio Séneca, Plinio e incluso Trajano ("emit fiscus quidquid videtur vedere"). En este sentido, vid. José M. BLANCH NOUGUÉS, Régimen jurídico de las fundaciones en derecho romano, Madrid: Dykinson, 2007, pp. 49 ss. En este mismo sentido, Gustavo, Penagos, Fundamentos del derecho administrativo: origen francés en el mundo. Bogotá: Librería del Profesional. 1993.

7 Fue Albert Dicey, profesor de Oxford, quien en su célebre An introdution to the study of the Law of the Constitution planteó la negación del derecho administrativo con fundamento en la doctrina del rule of law, donde la distinción de regímenes normativos, propia de la doctrina francesa, era a todas luces contraria a la igualdad sobre la cual se construyó el modelo inglés. Privilegiar a los sujetos públicos sobre los privados no está justificado (argumento de la igualdad), y el rule of law exige el sometimiento a un mismo y único derecho para todos (argumento normativo). Como dijera FRANCISCO MURILLO FERROL, "El régimen jurídico de la administración inglesa", Revista de Administración Pública n. ${ }^{\circ}$ 1, enero-abril, Madrid: 1950, p. 61: "Durante toda su vida intelectual, Dicey negó rotundamente la existencia en Inglaterra de un derecho administrativo en el sentido continental, postulando en contra la validez de su sistema de rule of law. Esto, como casi todas las cosas humanas, era verdad en un sentido y error en otro. Era verdad por cuanto ni siquiera en la Inglaterra actual ha tomado carta de naturaleza esa organización jurídica que se llama en Francia droit administratif; ni las normas, ni los procedimientos, ni las instituciones peculiares de éste existen 
mente que existía un cuerpo normativo de derecho que regulaba todo lo relacionado con la administración ${ }^{8}$, debemos nosotros entrar a reconocer que en aquel cuerpo consolidado de derecho romano (que no se preocupó por las clasificaciones, sino por la estructuración coherente de un sistema normativo) se consolidó un sistema jurídico propio que regulaba todo lo atinente a: la estructura pública, los servicios públicos, el orden público, los privilegios de la actuación pública y la forma en la cual se solucionaban los conflictos relacionados con sus dependencias, entre otras temáticas ${ }^{9}$.

Por ello, para poder reconocer la existencia de ese cuerpo normativo en el legado romano, y así, en un futuro, poder nutrir nuestro sistema y doctrina con dichas regulaciones, reconstruyendo adecuadamente la dogmática del derecho administrativo romano, entraremos primero a analizar las posturas que se han consolidado acerca del nacimiento del derecho administrativo, estudiando de manera clara y concisa cada una de ellas, para lograr determinar si es estrictamente necesaria la estructuración formal de la "administración pública" y de una disciplina administrativa (lo que se da con posterioridad a la Revolución francesa) para poder hablar de derecho administrativo, o si, en cambio, basta con constatar la existencia de ciertos elementos estructurales (tanto fácticos como jurídicos) que dan sustento al actuar de la administración. Para luego analizar, finalmente, algunas de las normativas romanas que integran el cuer-

en Gran Bretaña. En este sentido, Inglaterra no tenía un 'Régimen administrativo'. Es un error por cuanto la no existencia de un régimen administrativo en el sentido continental no implicaba la carencia absoluta de un derecho de la Administración, cosa totalmente incompatible con la esencia de todo Estado moderno".

8 Robson advierte que "aunque le demos la razón a Dicey reconociendo que no existe el droit administratif, esto no puede hacernos negar la existencia de un sistema de administrative law": WiLliam A. ROBSON, Justice and administrative law. London: Greenwood press, 1951, p. 26. Claramente esta aceptación posterior en cuanto a la existencia de un cuerpo normativo de derecho administrativo se dio por el cambio de papel que hasta entonces venía cumpliendo la administración pública. Pues fue luego del advenimiento de las teorías intervencionistas y del Estado de Bienestar que en dicho país se desarrolló esta idea. Concretamente, se dio en Inglaterra, con la consagración de normativas dirigidas a proteger ciertos derechos prestacionales, lo cual dio luces y demostró a los doctrinantes que por más que se niegue la existencia propia de una disciplina de este tipo, el Estado a través de su administración tiene un cuerpo normativo extenso y riguroso que enmarca toda su actuación, o como ellos lo llamarían, un sistema de administrative law.

9 En palabras del maestro FERNÁNDEZ DE BUjÁN, se puede "constatar la existencia de una compleja problemática administrativa en el seno de una sociedad, como la romana, en constante expansión y desarrollo, en la que se encuentran planteadas y satisfactoriamente resueltas las grandes cuestiones teóricas y prácticas del derecho administrativo actual, como: bienes patrimoniales y públicos, disponibles o no disponibles, obras públicas, concesiones y autorizaciones, servicios públicos prestados por sociedades privadas, justicia penal y administrativa, orden público, policía central, local, funeraria y edilicia, asistencia sanitaria, social e higiénica; prácticas religiosas; relaciones con la administración central": Antonio FernándeZ de BujÁn, Derecho público romano. 2. ${ }^{a}$ ed. Madrid: Civitas, 1997, p. 182. 
po de derecho especial que para la época regulaban la actividad pública, y más concretamente, lo que hoy llamamos "función administrativa", como un fenómeno empírico o práctico que se vivió para la época.

\section{PLANTEAMIENTOS DEL NACIMIENTO DEL DERECHO ADMINISTRATIVO}

El derecho administrativo cuenta, como se puede evidenciar, con un desarrollo amplio en su conceptualización teórica; dichas posturas toman como fundamento algunos de los elementos característicos de la misma construcción dogmáticoadministrativa, y de esa manera, con sustento en dicho elemento, sería posible ubicar el nacimiento en determinado punto histórico de esta disciplina jurídica. Sin embargo, en dicha construcción se hace notoria la tendencia a mantener una clasificación: por un lado, se tienen unas posturas que se reconocen por un momento cronológico de la historia (p. ej., Revolución francesa ${ }_{i}$ época del Estado absoluto -siglos XVII-XVIII-, ciencia cameral), y por otro, unas posturas que, aunque inicialmente no se plantearon para dar sustento al nacimiento de nuestro derecho especial administrativo, son el sustento de todo el fenómeno administrativo actual, son materializables y constantes en el tiempo y constituyen la piedra angular en la construcción teórica de nuestra ciencia. Estas últimas, las posturas teleológicas o finalistas que atienden al verdadero fundamento del derecho administrativo, serán las que permitan, finalmente, demostrar que la actividad realizada en Roma obedecía a fundamentos muy similares a los actuales.

Las primeras posturas las estudiaremos bajo la rúbrica de "posturas cronológicas", por encontrarse estas reconocidas con una circunstancia de tiempo y por ser fácilmente reconocible el momento histórico en el que ocurrieron; en cambio, a las que contienen un sustento plenamente teleológico o finalista (aunque puede verse en las posturas formales una influencia en algunos puntos de las teleológicas: $v$. gr., el cameralismo -postura cronológica- se ve influenciado en gran medida por la ciencia de la policía -postura teleológica-, aunque se pueden distinguir), les daremos el nombre de "posturas teleológicas" ${ }^{\prime 10}$. Nos ocuparemos primero, entonces, del estudio de las posturas cronológicas.

10 Esta clasificación obedece a la necesidad de escindir los acontecimientos históricos de la estructuración teórica en sí misma considerada, para con ello lograr demostrar que el nacimiento del derecho administrativo corresponde a un fenómeno práctico previo a la elaboración de la ciencia del derecho administrativo, concretamente, al reconocimiento formal de la "administración pública" en Francia o el "cameralismo" en Alemania o Austria. 


\section{POSTURAS CRONOLÓGICAS}

Estos planteamientos son reconocibles por su referencia a un momento histórico concreto en el que hay un cambio de concepción política, jurídica y/o social que da sustento a nuevas tendencias doctrinales. Dentro de estas analizaremos dos posturas teóricas: una primera, preponderante en la doctrina administrativa actual, según la cual el surgimiento del derecho administrativo se da solo con posterioridad a la Revolución francesa, con fundamento en unos elementos estructurales que a su vez constituyen novedad para las ciencias jurídicas del siglo XIX y XX; a esta se le reconoce como la postura acogida tradicionalmente ${ }^{11}$. Por otro lado, encontramos una labor teórica y práctica que se dio de manera particular en Alemania y Austria, países donde la doctrina del cameralismo influyó y ayudó a concebir la ciencia del buen gobierno y se manifestó en la búsqueda del mantenimiento del Estado y sus súbditos. A esta teoría suele llamársele como "ciencias camerales". A continuación acometemos el estudio de cada una de ellas.

\section{a. El surgimiento del derecho administrativo posterior a la Revolución francesa: la teoría clásica del origen del derecho administrativo}

La fragmentación del poder que caracterizó al feudalismo de la Edad Media se mostró insuficiente frente a las nuevas necesidades económicas que el mercantilismo exigía ${ }^{12}$; es por eso que se necesitó la conformación del "Estado moderno", el cual concentraría en una persona todo el poder y consolidaría el concepto de soberanía enunciado por Bodino ${ }^{13}$; era inevitable que tal concentración de poder generara una disconformidad acumulada en los diferentes estamentos ante el despotismo de un rey todopoderoso instaurado en el poder por designio divino; este es el claro ejemplo de lo sucedido en Francia, y la razón principal por la que el 7 de julio de 1789 los Estados Generales se autoproclamarían como asamblea nacional constituyente, utilizando por primera vez este término que significa en la Modernidad la máxima expresión de poder y voluntad popular, para terminar después en el estallido de una revolución

11 En este sentido, Libardo RodríGuez RodrígueZ, "La explicación histórica del derecho administrativo". Estudios en homenaje a don Jorge Fernández Ruiz. Derecho administrativo. México D.F.: Universidad Nacional Autónoma de México, 2005, p. 295; Miguel Alejandro Malagón Pinzón, "La Revolución Francesa y el Derecho Administrativo Francés. La invención de la teoría del acto político o de gobierno y su ausencia de control judicial", Diálogos de saberes: investigaciones y ciencias sociales, Bogotá: Universidad Libre, n. ${ }^{\circ}$ 23, 2005

12 JORGE IVÁN RINCÓN CÓRDOBA, Las generaciones de los derechos fundamentales y la acción de la administración pública. Bogotá: Universidad Externado de Colombia, 2004, p. 30.

13 Augusto Hernández BeCERRA, Las ideas políticas en la historia, Bogotá: Universidad Externado de Colombia, 2001, p. 202. 
sin precedentes, que pretendía, y efectivamente logró (en cierta medida), cambiar el mundo y las doctrinas imperantes para el momento. La Revolución francesa significó entonces un cambio drástico en las concepciones de Estado y sociedad; se trató de un movimiento que buscaba una reivindicación con el hombre: "se pretendía, nada más y nada menos, rectificar la historia entera de la humanidad, fundar un nuevo orden político y social completamente nuevo, capaz de establecer una nueva etapa de la trágica evolución humana y de asegurar para el futuro una felicidad segura e inmarchitable"14.

Como resultado de ese drástico cambio lingüístico ${ }^{15}$, político y social, parte de la doctrina clásica afirma que el origen del derecho administrativo está ligado a la implementación del "Estado constitucional" o Estado de derecho, y este momento indefectiblemente coincide con la Revolución francesa y los años inmediatamente siguientes ${ }^{16} ;$ se trata entonces de esa sujeción de todos los ciudadanos al derecho, pero no solo estos, sino también sus gobernantes ${ }^{17}$, es decir, todo el aparato estatal ya no podría actuar con total arbitrio como lo hacía antes, sino que ahora estará sometido y deberá actuar según los lineamientos que la ley permita. La ley vendrá a ser, entonces, "el código de conducta de los funcionarios de la administración, quienes en adelante solo podrían hacer lo que les estaba permitido expresamente por ella. Los funcionarios se convirtieron así en meros agentes del poder soberano que se encarnó en el parlamento, único órgano investido de la representación popular"18.

La soberanía ya no estaba ni recaía en el príncipe, sino en la Nación, y solo en el Parlamento se veía representada esta i es por eso que el Estado debía estar sometido a la ley, pues solo la ley es la expresión de la voluntad general ${ }^{19}$. En este momento histórico se ve cómo los revolucionarios tomaron el concepto de soberanía, que ya existía, y lo adaptaron a su nuevo modelo de Estado; a partir de aquí, "el poder se convierte en algo terrenal y en un instrumento al

14 Eduardo García De Enterría, La lengua de los derechos. La formación del derecho público europeo tras la Revolución francesa, Madrid: Alianza, 1994, p. 20.

15 Es especialmente interesante cómo GARCÍA DE ENTERRÍA, en la obra antes citada, expone apasionadamente la importancia del lenguaje, no solo en el desarrollo de la Revolución, sino también en el éxito y trascendencia que caracterizaron a este momento de la historia. "Cuando la declaración dice 'los hombres son libres e iguales', quiere decir: 'convengamos que, a partir de ahora, los hombre serán...', de modo, observa Maille, que desde el momento en que la frase se pronuncia produce el efecto de su propio contenido, haciendo acceder a la realidad la libertad y la igualdad".

16 LuCiano Parejo AlONSO, El concepto del derecho administrativo, 2. ${ }^{a}$ ed., Bogotá: Universidad Externado de Colombia, 2009, p. 120.

17 RodríGuez RodríGueZ, ob. cit., p. 295.

18 Miguel Alejandro Malagón Pinzón, Vivir en policía. Una contralectura de los orígenes del derecho administrativo colombiano, Bogotá: Universidad Externado de Colombia, 2007, p. 27.

19 Artículo 6 de la Declaración de los Derechos del Hombre y el Ciudadano: "Le loi est l'expresión de la volonté generale". 
servicio de la humanidad, atrás quedaba la idea de misticismo y religiosidad que acompañaba a los príncipes, para ser reemplazada por la razón que permitía que se designara a un nuevo titular de la soberanía, el pueblo representado [... en la Nación como persona abstracta donde se depositaban los intereses de la sociedad revolucionaria" 20 .

Solo después de sometida la administración al "derecho" (propiamente a la ley) podría desarrollarse lo que conocemos hoy como derecho administrativo; es entonces el concepto revolucionario de imperio de la ley el que constituye el presupuesto jurídico que permite el origen de esta rama del derecho; visto, claro está, desde esta postura.

Además del principio de legalidad acabado de mencionar, es particularmente relevante el concepto de división del poder (actualmente nombrado como división de funciones) de Montesquieu, que, no debe olvidarse, ya había sido desarrollado por Aristóteles y posteriormente por Locke ${ }^{21}$, recordando que, entre ambos, Polibio también hizo alusión a tal principio, y lo evidenció en su concepto de la constitución romana en la época de la República tardía ${ }^{22}$ Sin embargo, en De l'esprit des lois se hizo la clara diferenciación de las tres funciones del Estado, lo que sería el principio cardinal sobre el que se asienta el Estado constitucional revolucionario ${ }^{23}{ }_{i}$ es entonces este el presupuesto político necesario para la existencia, según los revolucionarios, del derecho administrativo; el cual partiría de la necesidad de evitar la excesiva concentración del poder. Sin embargo, en el modelo francés parece haber un lugar preferencial para el Parlamento, pues las demás funciones estaban subordinadas a este y a la repartición de competencias que el mismo hiciera ${ }^{24}$. Según esta tesis, solo una vez rígidamente diferenciadas las ramas del poder público, y sujeta la administración a la ley, podía encontrar su génesis el derecho administrativo. Sin embargo, en dicha tesis se ignora que los conceptos de interés público, bienestar general, policía y servicio público no son solo los que fundamentan el derecho administrativo, sino los que constituyen su punto de partida y origen, son el propio objeto de nuestra materia. Ahora bien, analizando otros momentos históricos desconocidos por esta teoría, se puede evidenciar

21 Malagón PinZÓn, ob. cit., p. 30.

22 Polibio hace referencia a la repartición del poder en la constitución romana, y señala la dificultad para la época de distinguir cuál institución (si el consulado, el senado o el pueblo) prevalecía, en razón de la participación equitativa que cada uno tenía en los asuntos públicos. "Así pues, estas tres clases de gobierno [...] dominaban la constitución y las tres estaban ordenadas, se administraban y repartían tan equitativamente con tanto acierto, que nunca nadie, ni siquiera los nativos, hubiera podido afirmar con seguridad si el gobierno era totalmente aristocrático, democrático o monárquico": FABIO ESPITIA GARZÓN, Historia del derecho romano, Bogotá: Universidad Externado de Colombia, 2016, pp. 104-105. 
un fenómeno que atiende a la regulación de estas temáticas y a dar solución a problemas similares a los que preocupan a la disciplina administrativa actual. Por tanto, son estos los que verdaderamente nos permitirán, a ciencia cierta, determinar la existencia o no del derecho administrativo.

\section{b. El surgimiento del derecho administrativo en el estado absoluto: las ciencias camerales}

El cameralismo fue, inicialmente, una corriente del mercantilismo difundida principalmente en Alemania y luego en Austria durante los siglos XVII y XVIII; se refiere a un conjunto de interacciones entre ciertas actitudes "político-económico-institucionales" correspondientes a la formación del Estado moderno alemán, y representa una concepción administrativa del Estado desarrollada en este país durante dicho período histórico. Tuvo inicialmente una connotación económica, por lo cual adquirió un papel relacionado con las finanzas públicas. Las prácticas o aproximaciones del cameralismo fueron formalizadas en 1762 por el austriaco Johann M. Puechberg, sin embargo, el catedrático cameralista más conocido fue Johann H. G. von Justi.

Como disciplina, el cameralismo empezó simplemente como una política dirigida a fortalecer las finanzas reales. Así, la única medida de interés de la riqueza de un país era la cantidad de impuestos que era posible recaudar. Sobre esa base se empezaron a buscar políticas que promovieran las actividades económicas de los diferentes principados germanos de la época, y a obstaculizar las "importaciones". Al mismo tiempo, se empezaron a desarrollar sistemas que permitieran la recaudación efectiva de impuestos y tributos. Durante este período la finalidad explícita de las políticas y prácticas fiscales era el fortalecimiento del Estado ${ }^{25}$, que se veía personificado en la persona del monarca.

Guerrero Orozco dice al respecto: "El cameralismo tiene su raíz en la Cámara, la cual era una especie de organización colegiada, cuya finalidad era atender todos los asuntos administrativos del Estado, estaba compuesta por una serie de centros de decisión y de poder en los cuales privaba el consenso,

25 "El cameralismo representaba un movimiento político organizado por los funcionarios públicos germanos formados empíricamente para conocer, instrumentar y sostener el Estado absolutista; sin embargo, ellos consideraron la necesidad de establecer criterios pedagógicos para facilitar la continuidad histórica del cameralismo y del mantenimiento del absolutismo": Alice J., Araujo Lobo, "Cameralismo: un antecedente más en la evolución de la administración como ciencia", Revista Visión Gerencial año 14 n. ${ }^{\circ}$ (Enero-Junio). Caracas: Universidad de los Andes (Venezuela), 2015, p. 171. Además, debe tenerse en cuenta que el cameralista es un administrador público formado cabalmente en la totalidad de los negocios gubernamentales, pero no sólo por la vía de la experiencia personal, sino también por el aprendizaje universal y sistemático proporcionado por las universidades. El cameralismo muestra cómo el estudio del objeto de la administración pública sirve para el mejoramiento del Estado, su consolidación, permanencia y desarrollo. 
[y] era asistida por una secretaría integrada por oficiales administrativos que tenían como tarea redactar los acuerdos camerales, archivar la documentación y despachar los negocios ${ }^{\prime \prime 26-27}$.

Cabe señalar que, como ideología, el cameralismo comprendió, entre los primeros años del siglo XVI y la primera mitad del XIX, cuatro etapas ${ }^{28}$ :

1. La etapa original, desde principios del siglo XVI al año 1656, caracterizada por su combate contra el todavía poderoso feudalismo.

2. La etapa sistemática, desde 1656 hasta 1727 , durante la cual se funda el estatuto académico de las ciencias camerales y se escriben sus programas de acción.

3. La etapa académica, entre 1727 y 1755 , durante la cual se establece la cátedra "Profesión en Economía, Policía y Cameralística", de donde nacen las ciencias camerales propiamente dichas.

4. La etapa científica, desde 1755 hasta 1848 , en la cual se desarrollan teóricamente las ciencias camerales a partir de la notable obra de Juan E. von Justi (de quien hablaremos más adelante) Elementos generales de policía ${ }^{29}$, publicado en 1756 .

26 "Los miembros de la cámaras son los cameralistas, o funcionarios estatales que laboran en su seno. Pero no se trata de simples burócratas, constituyen un grupo de altos oficiales públicos cuyo propósito, más que mantener un estado de cosas que tiene todavía remanentes feudales, está encaminado a fortalecer una nueva forma de entidad política: el Estado absolutista. Al efecto, sus esfuerzos son plasmados en programas de acción, frecuentemente redactados en libros de amplia difusión entre los funcionarios absolutistas y los medios intelectuales": Ómar, Guerrero Orozco, Las Ciencias Camerales, Revista Ensayos, vol. II, n. ${ }^{\circ}$ 6. México D.F.: Unam, 1985, p. 17.

27 Dichos órganos asesores del monarca tienen plena influencia romana, en cuanto toman su sustento en el "concilium principis" que luego de Augusto, en plena época del Principado, tomó gran importancia en la gestión pública, llegando incluso, con los años, a convertirse en una institución profesional, especializada y técnica integrada por personas que tenían que cumplir con una serie de requisitos formales y materiales para acceder al cargo. En este sentido, Gustavo Penagos, Fundamentos del derecho administrativo: origen francés en el mundo. Bogotá: Librería del Profesional. 1993, p. 21 ss.

28 Varios doctrinantes utilizan esta clasificación como un modelo didáctico que explica la forma de desarrollo de la teoría cameral. Especialmente, en este sentido: GUERRERO OrOZCO, ob. cit., p. 17.

29 "Con von Justi ese movimiento alcanza su etapa superior, porque él entiende los conceptos como categorías científicas. Pero en su pensamiento destaca la policía, que antes del siglo XVIII no se había concebido adecuadamente al permanecer incógnita dentro de un mundo gubernamental indiviso; era todavía un suceso anónimo e indiferenciado dentro de otros fenómenos estatales": Ómar Guerrero Orozco, Von Justi y la ciencia de la policía. retrospección y prospectiva. Memorias, Segundo Congreso Internacional de Ciencia de Policía (octubre). Bogotá. 2011, pp. 2 ss. 
Teniendo en cuenta las fases de evolución del cameralismo, es preciso distinguir dos épocas relacionadas con el mismo: la primera, correspondiente a la antigua actitud medieval tardía y de la primera Edad Media, cuando los consejeros del príncipe le recomendaban a este sobre el "arte de gobernar", denominado movimiento cameralista, donde apenas se introducía la forma de Estado. La segunda, correspondiente propiamente a las ciencias camerales o cameralísticas, cuyo propósito era la construcción y sobrevivencia del Estado absolutista moderno, que se veía amenazado por las nuevas tendencias filosóficas, sociales y políticas (período post consolidación y caída del Estado absoluto $)^{30}$.

Pero el absolutismo no solo sostiene una doctrina académica, es asimismo una ideología de un tipo de Estado: el absolutista, al cual defiende y promueve. Como ideología, el cameralismo es una fuerza superestructural que contribuye a la comunión intelectual y política de los cameralistas ${ }^{31}$, es una fuerza irresistible de unión.

Fue bajo la influencia de la Ilustración que, posteriormente, esa imagen empezó a cambiar. Aunque el poder de los monarcas llegó a ser absoluto, con la Ilustración aparece el concepto de monarquía ilustrada, cuya función era, especialmente en Alemania y, un poco menos, en Austria, traer progreso, bienestar social y económico al pueblo, con la asesoría de sus funcionarios, por medio de reformas y demás mecanismos útiles para la efectiva consecución de los fines, estableciendo así las bases para un sistema de administración cuyo objetivo deja de ser solo el interés del monarca y es complementado por la llamada "utilidad pública".

Es en este período que el cameralismo se implementa como disciplina académica con estudios formales, impuestos por el monarca para su enseñanza en las universidades; todo llevó a que esos estudios "cameralísticos" incluyeran las áreas de: "Cameralismo" (o administración, especialmente lo que después fue llamado "Administración pública"), "Oeconomie" (o Finanzas) y "Polizei" (o policía).

Ahora, en la medida en que los monarcas asumen la responsabilidad de la dirección económica general y la responsabilidad de asegurar el bienestar de sus sujetos, se ven obligados a expandir sus ámbitos de acción y a buscar los mecanismos más idóneos para la manutención del Estado absoluto y del

30 Norberto Bobbio y Nicola Matteucci (dirs.) (1987). Diccionario de Política, 5. a ed., Homero Alemán, Juan Jacobo Simón y Haydée Valero (trads.). México D.F.: Siglo Veintiuno. 1976.

31 "Son disciplinas académicas susceptibles de ser enseñadas por medio de la cátedra, capaces de ser aprendidas mediante ejercicios del raciocinio. Por lo tanto, son un vehículo docente, una vía pedagógica para que los funcionarios estatales conozcan los mejores medios para alcanzar el bienestar del Estado y la felicidad de los súbditos. Todas ellas son ciencias administrativas porque existen para hacer cumplir las funciones de la administración pública en pro del bienestar estatal y la felicidad de la población": GUERRERO, ob. cit., p. 18. 
bienestar general ${ }_{i}$ necesitan por ende incrementar las capacidades productivas, introducir mejoras técnicas, adaptar en la práctica la contabilidad y las partidas presupuestarias, así como encontrar maneras de implementar una nueva, revolucionaria y fuerte actividad estatal, encaminada a asegurar la felicidad y prosperidad de sus habitantes hasta donde fuera posible (el monarca y su cámara se constituyen en una especie de posición de garante donde los súbditos se someten al poder sólo a condición de que se dé la efectiva contraprestación del monarca: protección, cuidado, bienestar, felicidad, entre otras cuestiones ${ }^{32}$.

Estos funcionarios o cameralistas debían definir las fuentes fiscales potenciales, organizar el Estado, hacer trabajar productivamente a los súbditos y hacerles comprender los métodos que los pudieran enriquecer, así como crear oportunidades para que cada cual aplicara sus conocimientos y conservara sus ingresos; es decir, el cameralista debía esforzarse para convertir a los súbditos en seres productivos y realizados; él era un agente comprometido con el bienestar de la sociedad y la prosperidad del Estado.

Se evidencia entonces que las ciencias cameralísticas constituyen un bastión teórico muy significativo difundido en algunos países europeos, que pudo haber influenciado las mentes de quienes, posteriormente, se convertirían en los padres de la administración. Quizás su principal característica es que sirvieron de medio o vehículo para que el Estado alemán lograra de manera más eficiente y organizada unos fines determinados; es decir, tuvieron un carácter utilitario, bondades que hoy también se le atribuyen a la moderna ciencia de administración. La administración, en general, surge para servir a la sociedad, en un primer momento, para conservar y organizar su forma de gobierno y a ella misma; luego, sirve para ayudar a las organizaciones tanto públicas como privadas a proveer los bienes y servicios que demanda dicha sociedad.

El movimiento cameralista sufre una transformación profunda en el año de 1727, debido a que se transforma en las ciencias camerales, a saber: la economía, la policía y la cameralística (o cameraliaj). Al pasar el tiempo, a mediados del siglo XIX, todavía seguían siendo tres las ciencias, pero diferentes: Policía ${ }^{33}$, Comercio y Finanzas ${ }^{34}$.

32 Pudiéndose ver una especie de garantismo por parte del monarca, lo cual se puede asimilar a la construcción teórica del Estado de Bienestar.

33 La ciencia de la policía estaba encauzada a nutrir las fuerzas interiores y exteriores del Estado moderno que empezaba a surgir en el siglo XVI. La policía es una disciplina que nace, se desarrolla y extiende entre los siglos XVI y XVIII, principalmente en Alemania, Francia y España.

34 "Las ciencias camerales eran enseñadas bajo el mismo programa docente, pero atendiendo cada cual su propia materia. Los profesores cameralistas definían por separado la economía, la policía y la cameralística.

"Esta última, cuyo objeto de estudio y enseñanza eran los principios de la óptima administración del patrimonio del Estado, es decir, de sus bienes y recursos propios, era una especialidad académica consolidada. 
Para finalizar con el cameralismo es necesario hacer hincapié en aquella teoría que posteriormente adquirió identidad propia: la ciencia de la policía. Su primera definición se identificaba con la conservación del buen orden de la comunidad: el gobierno, la administración y el orden interior. Luego, en la obra política Para Corregidores de Castillo de Bovadilla, escrita en 1597, se asimiló policía a politeia, y se señaló que esta significaba "buena gobernación de la ciudad que abraza todos los buenos gobiernos, que trata y ordena las cosas corporales que tocan a la policía, conservación y buen encaminamiento de los hombres" ${ }^{\prime \prime 3}$.

Pero además, como lo veremos más adelante, la evolución del concepto continúa, agregándose al anterior el "eudemonismo", postura según la cual la policía busca el bienestar de los súbditos, su felicidad ${ }^{36}$, que fue añadida casi a la caída del absolutismo. Luego el concepto viene a transformarse según las características de la sociedad, sin embargo empieza a distinguirse desde ya una ciencia de la policía de seguridad y otra de bienestar, como veremos.

Para terminar, se debe resaltar en primer lugar los aportes realizados por estas posturas, pues ellas, en su ámbito propio, ayudan al desarrollo del derecho administrativo estableciendo una serie de elementos que hoy en día son base de nuestra disciplina jurídica administrativa (p. ej., el principio de legalidad en la postura clásica post Revolución francesa, o la ciencia de la policía en el cameralismo). Sin embargo, se equivocan al establecer que dicho momento histórico es, única y exclusivamente, el momento determinante del nacimiento del derecho administrativo, sin tener en cuenta el desarrollo de nuestra materia, el cual se dio dentro de un proceso histórico, y sin tener en cuenta dichas construcciones modernas realizadas con fundamento en esos acontecimientos históricos, pues, como sabemos, el derecho, el Estado y la Administración, antes que ser fenómenos jurídicos reconocidos formalmente, son una construcción social e histórica que se fundamenta y desarrolla con

"La economía, por su parte, estaba relacionada con todo aquello que hacía brotar riqueza, se preocupaba por la producción y el consumo, por el comercio y el tráfico en el seno vital de las entrañas productivas de la sociedad civil.

"Finalmente, la policía, ciencia cameral que con todo tino ha sido identificada con la médula de la moderna ciencia de la administración, era la disciplina que por medio de sus bien diseñadas tecnologías administrativas cuidaba que la economía produjera bienes y servicios en la sociedad, y de esa manera, la cameralística lo haría en el Estado, si se pudiera decir de ese modo": GUERRERO, ob. cit., p. 18.

36 Postura proveniente de los planteamientos de Christian Wolff, de la escuela de derecho natural racional, según la cual se predica la idea de pacto social y se entiende que la felicidad de cada uno no sería otra cosa que la contrapartida que todo individuo puede pretender de la entidad abstracta a la que el pacto social le ha sacrificado la libertad originaria: el Estado. Citado por MALAGÓn PINZÓN, ob. cit. 
base en los requerimientos y problemáticas de un grupo ${ }^{37} ;$ a partir de dichos requerimientos y necesidades es que se consolida y estructura un derecho para la administración y su actuación.

Ahora, en lo atinente a la Revolución francesa debemos decir que:

1. Con respecto al presupuesto jurídico, el principio de legalidad, si bien es la base del Estado constitucional, no podrá ser la esencia del derecho administrativo, pues únicamente es un lineamiento añadido como consecuencia de un momento histórico (siendo además un elemento novísimo en la teoría moderna), en donde la preponderancia de la arbitrariedad y la falta de gestión eficiente del Estado llevaron a replantear el modelo estatal y los límites del poder, pero como una respuesta concreta de esa sociedad al régimen imperante. Filosóficamente es necesario someter a un "verdadero" límite la actuación del detentador del poder, lo cual se logra solo con sustento en el interés general, pero ello no obsta para que se desconozca, de tajo, los fenómenos jurídicos que se dieron en épocas precedentes y que no se sustentaron en el sometimiento pleno a una normativa, si bien dieron respuesta a las grandes necesidades de una sociedad en constante evolución y que, como la romana, más que preocuparse en la construcción teórica y articulada de una disciplina, se preocupó por efectivamente dar regulación a los temas complejos que surgieron en la época.

2. Respecto al presupuesto politico, el principio de división del poder (o como hoy lo llamaríamos, de división de funciones), además de no ser una innovación de la Revolución francesa, pues ya se presentaba, como se expuso anteriormente (supra I.2.a), en otras construcciones precedentes, lo que efectivamente logró con respecto a este punto fue diferenciar, formalmente ${ }^{38}$, a un nuevo sujeto: la administración pública.

37 Pues es de esta misma manera que Malagón Pinzón plantea, desde su enfoque administrativo, un nacimiento diferenciado para Colombia del derecho administrativo, pues "el derecho administrativo es un derecho mucho más antiguo de lo que la mayoría de nuestros autores plantean": MALAGÓN PINZÓN, ob. cit., p. 13. Criticando así, fuertemente, la posición francesa extendida universalmente pero que obedecía a una sociedad concreta: la de Francia del siglo XIX y XX. Es por ello que debemos analizar de manera independiente a cada sociedad y estudiar el fenómeno práctico en el cual se desarrolla el derecho administrativo.

38 Formalmente, en cuanto en el devenir histórico se ve la estructuración de un ente público que cumple funciones afines a las que cumple esta nueva administración pública en la nueva estructura francesa y que se relaciona de la misma manera con los asociados con el fin de brindarles bienestar y seguridad, entre otras cosas; pero aun no se le llama, reiteramos, administración. Además de que el simple reconocimiento formal de un "ente" público especial de este tipo no puede llevar a concluir que se ha distinguido el derecho administrativo del derecho común, en cuando el fenómeno administrativo es más amplio y no se circunscribe a un solo sujeto; de otra manera se desconocerían los múltiples desarrollos 
Sin embargo, el derecho administrativo no se sustenta, circunscribe y define únicamente como el derecho que desarrolla las actuaciones que realiza la administración pública, es decir, el derecho administrativo no solo se desarrolla en cabeza de dicha entidad (se trata de un fenómeno mucho más amplio), sino que se sustenta y define como un derecho de la actuación administrativa ${ }^{39-40}$. Es por esto que distinguir a un ente público llamado "administración" no puede ser ni conllevar, de manera plena y certera, la distinción de un derecho especial administrativo, eso sí, dicha concepción política, fruto de la respuesta concreta de la sociedad francesa a un régimen opresor y arbitrario como el que se vivió en dicho Estado para la época, ayudó en la construcción de lo que hoy llamamos "disciplina de derecho administrativo"; pero se trata de una construcción más avanzada del primigenio y simple derecho administrativo, y más aún, de aquellas regulaciones propias de un derecho para la administración, que para nosotros se presentó antes de la Revolución y, más concretamente, en Roma.

En lo atinente al cameralismo, es pertinente anotar que no se trata de una explicación plena del origen del derecho administrativo, sino que corresponde a un momento histórico en el cual se comenzó a dar un planteamiento académico y práctico que se basaba en el buen gobierno y la estructuración coherente de unas normas para gobernar eficientemente. De esta posición teórica se rescata la ciencia de la policía, como un sustento material que buscaba el desarrollo eficiente del Estado y la sociedad. Sin embargo, por tratarse de una construcción teórica ligada a un momento concreto de la historia (siglos XVII y XVIII), se descarta, pues antes que esa construcción hubo un desarrollo normativo que se dio en Roma frente a la administración y la función que esta y otros sujetos podían ejercer: la actividad administrativa ${ }_{i}$ y es por ello que, aunque dan muestra de un derecho administrativo, no son un punto determinante de su nacimiento, ni mucho podrían desconocer construcciones precedentes que tienen una base fáctica similar.

sobre la función administrativa, desarrollos que se dan en atención a las necesidades del grupo y su posterior solución con la actuación pública.

39 "El derecho administrativo debe tener un referente material y sus análisis estructurales, estáticos o subjetivos deben estar condicionados a aquél. El derecho administrativo debe ser consecuente con las finalidades constitucionales de los Estados actuales, y con la lógica económica y social también constitucional de éstos, antes que con las calificaciones formales que se hagan de los sujetos de derecho": AlberTo MonTAÑa PlatA, Fundamentos de derecho administrativo. Bogotá: Universidad Externado de Colombia, 2010, p. 123.

40 "Una consideración exclusivamente orgánica (subjetiva) no nos lleva fácilmente a la identificación de unos rasgos o características comunes suyas, que, en cambio, más fácilmente pueden ser concebidas a partir de un razonamiento material (objetivo)": ibíd., p. 165 
Por último, es necesario reiterar que, aunque estas posturas cronológicas (especialmente la francesa) marcaron el cambio de ideario político, jurídico y social, que para el momento imperaba, lo cual conllevó el reconocimiento formal de la "administración pública" y el desarrollo de una ciencia del derecho administrativo, no son suficientes para explicar el nacimiento de este derecho, ni pueden desconocer los múltiples desarrollos normativos que originaron un aparato administrativo con el cual se solucionaron las diferentes problemáticas de la época, y que, siendo el hombre una constante, siguen siendo objeto de estudio en la actualidad, tal y como se mostrará. Por ello se hace necesario acudir a otra perspectiva jurídica, apegada a la realidad histórica pero sin limitarse a ella, desde la cual sea posible mirar aquellas temáticas primordiales y estructurales de nuestra disciplina jurídica y, a partir de la mismas, evidenciar un sistema normativo claro y distinto que se encargue de suplir las necesidades sociales y estatales: la actuación administrativa.

\section{Posturas teleológicas}

Antes de entrar de lleno a considerar las posturas teleológicas o finalísticas, es necesario realizar la misma aclaración hecha al inicio del análisis de todas las teorías, y es que, aunque indudablemente el fundamento de esta clase de posturas es un sustento meramente teórico, sin tener en cuenta ni reconocerse un solo momento histórico para su creación, se debe admitir, no obstante, que esta clase de posturas sí tienen períodos en los cuales se desarrolla en mayor medida la teorización, su expansión y desarrollo ${ }^{41}$ (p. ej., en los inicios del siglo XX, cuando se desarrolló plenamente la teoría del servicio público en la escuela de Burdeaux $)^{42}$; se puede decir que dichos años son primordiales para la estructuración de la teoría, pero ella llega más allá sin quedarse en un fenómeno meramente temporal ${ }_{i}$ además, téngase en cuenta que, en algunos puntos,

41 Dichas posturas, sin embargo, no son una estructuración doctrinal que buscara determinar el nacimiento del derecho administrativo, pues en verdad se preocupan por la sistematización coherente de la actuación administrativa (como objeto propio del derecho administrativo), dándole un sustento material al mismo.

42 "La frecuente conceptualización del derecho administrativo a partir de los servicios públicos no es circunstancial, obedece a la consideración de un elemento constitutivo que ha estado presente siempre, y no sólo en los momentos históricos concretos en que las inspiraciones ideológicas han tenido incidencia determinante en las respectivas construcciones teóricas": Alberto Montaña Plata, El concepto de servicio público en el derecho administrativo. Ed. 2. Bogotá: Universidad Externado de Colombia. 2008, pp. 126-127. También nos dice este autor que "las elaboraciones teóricas de Duguit y en general de la École du service public han sido trascendentales en la consolidación del rol de los servicios públicos en el seno del derecho administrativo entendido como derecho de la administración pública. Sin embargo, este aporte teórico no puede verse como la circunstancia precisa que determinó esta valoración, sino como un momento más en su evolución, que se caracterizó desde su inicio por la consideración de estos servicios" (ibíd., p. 127). 
las posturas cronológicas también se nutren de las teleológicas, pero esto no obsta para que nosotros, en nuestra labor académica, podamos distinguir plenamente los fundamentos $y$, así, estemos en condiciones de conformar una teoría más sólida; en efecto, aunque unas y otras posturas se lleguen a conectar en algunos puntos, podemos distinguir una de otra (p. ej., la ciencia de la policía tiene gran sustento en la cameralística alemana y austriaca, y sin embargo su desarrollo también se dio en España y Francia ${ }_{i}$ además, se desligó casi completamente de ese momento histórico, llegando más allá, como lo veremos).

En nuestro estudio estas posturas que llamamos teleológicas (aquellas que señalan un elemento fundamental para la existencia del derecho administrativo, es decir, se trata del objeto estructural que permite su origen) las usamos posteriormente para mostrar que, en caso de estar presente dicho objeto en la estructuración del derecho de un grupo, se puede afirmar la existencia de un derecho administrativo. Es justamente por esto que, con fundamento en ellas, plantearemos, a partir de la presencia de esos elementos en Roma (junto con las demás estructuras normativas), la existencia de un derecho administrativo romano.

\section{a. La ciencia de la policía}

La figura de la policía tiene sus orígenes en el concepto de polis griega, y a pesar de que en la actualidad se la suele asociar con el orden público, la policía tiene alcances que van más allá de este. Recordemos al respecto a Sócrates, quien de forma casi poética señalaba a la policía "como el alma de la ciudad, operando en ella los mismos efectos que el entendimiento en el hombre; siendo la que piensa en todo, la que regula todas las cosas, la que hace o procura todos los bienes necesarios a los ciudadanos, y la que aleja de la sociedad todos los males y todas las calamidades que son de temer ${ }^{\prime \prime 4}$. Sin embargo, es Aristóteles quien ofrece un concepto más tangible, al definirla como "el gobierno de la ciudad, el sostén de la vida del pueblo, el primero y el más grande de los bienes" ${ }^{\prime 4}$; es decir, muy asemejado a la politeia, es esa buena administración de la res publica, designándola pues como el buen gobierno público de la ciudad y del Estado. Se suele relacionar al origen de la policía, tal y como lo expusimos, con la cameralística originada en Austria y Alemania, que correspondía en principio a ese consejo o cámara del príncipe que se encargaba de la política internacional, las finanzas y la administración ${ }^{45}$. precisiones sobre el concepto de policía", Revista de Administración Pública, Madrid: Centro de Estudios Políticos y Constitucionales, n. ${ }^{\circ} 81,1976$, p. 38. 
La definición de la ciencia de la policía ha tenido una historia intrincada, pues, tal y como lo expresa Guerrero Orozco, aun en el seno de la cameralística el concepto no era claro ${ }^{46}$; eran evidentes los intentos por deslindar esta materia de las demás; es así como Van Justi se encargó de expresar, por ejemplo, las diferencias entre la policía y la política, caracterizando a esta última con un componente más negativo de conservación, y a la primera con "la función positiva de nutrir, paralelamente, la vida de los súbditos y la fuerza del estado" 47 , sin de ninguna manera contraponerlas; también se diferencia de la administración de justicia, la cual marcha paralelamente con la policía "para asegurar un nivel optimo de civilidad"48 ${ }_{i}$ por tanto se fue formando un conjunto de normas encaminadas a la administración y a la búsqueda del bienestar general, no al mero beneficio del príncipe ${ }^{49}$.

Parejo Alonso señala como objeto de la policía tres elementos: la búsqueda de la felicidad y el bienestar de los súbditos; la sistematización conforme a principios generales de las múltiples reglas dictadas por el monarca para mejorar el viejo orden de las cosas (un poder real que asume el papel del progreso), y el proceso de reforma social asumido por el Estado absoluto según las ideas del Renacimiento ${ }^{50}$. Pero no se debe olvidar que en Roma ya había una estructura burocrática con funciones similares, en principio con el concilio creado por Augusto, el cual se dedicaba a labores de administración y justicia, entre otros, y luego con el ya mejor estructurado consistorio de Diocleciano ${ }^{51}$;

"DithmaR opinaba que la ciencia de la policía enseña cómo mantener el sistema interno y externo del Estado con buena policía, en función de la felicidad general. La policía era la vida y el alma del Estado. DANIEL SCHREBER sostenía una versión similar: pensaba que la policía se refiere a la adecuada organización de los hombres y los recursos económicos con miras a la consecución de la felicidad de la sociedad. Por su parte, ANDREAS BERCH afirmaba que a través de la policía, los miembros de la comunidad se mantienen en buen orden y pueden de tal modo perseguir con mayor eficacia sus asuntos individuales, que pertenecen a la esfera económica. En 1752, ZINCKE señalaba que la policía tiene la tarea de dirigir y promover los medios de vida y la dirección del pueblo. Finalmente, SonNENFELS comentaba que, cuando las decisiones y los proyectos están unidos y se refieren a ciertas máximas derivadas de los principios sociales, nace la ciencia del mantenimiento de la seguridad interna del Estado: la ciencia de la policía": GUERRERO OROZCO, ob. cit., p. 10 . Ibíd., p. 18.

"La evolución del concepto continúa y se agrega a la anterior el eudemonismo, o mejor la postura según la cual la policía busca el bienestar de los súbditos, su felicidad": MALAGÓN PINZÓN, ob. cit., p. 155

50 Parejo Alonso, ob. cit., p. 143.

51 "En tiempos de Diocleciano se creó una figura nueva denominada el consistorio; no difería mucho del anterior (concilio), y en ella se dividieron los cargos en superiores e inferiores: los primeros eran el canciller, el maestro de oficios, el ministro de hacienda y el ministro del tesoro real ${ }_{i}$ los segundos eran reconocidos miembros de las oficinas administrativas": MALAGÓN PINZÓN, ob. cit., p. 151. 
estos elementos se analizarán más adelante, siendo por el momento suficiente resaltar la existencia de estructuras dedicadas a la correcta administración.

A pesar de los fines generosos y nobles que recubrieron a la ciencia de la policía en razón del eudemonismo, no se puede ignorar que estos coexistían con otros mucho más discutibles; sin bien existía consenso sobre la búsqueda de el buen manejo y sobre la protección del interés público, hay que recordar que el concepto de policía también se refería a la necesidad de velar por la permanencia y fortalecimiento del poder del príncipe ${ }^{52}$, superando de esta manera los problemas ligados a la fragmentación que caracterizaba el feudalismo:

La existencia de este doble juego no podía permanecer oculta indefinidamente. En un principio, los súbditos del monarca absoluto aceptaban con agradecimiento la tutela policial, puesto que gracias a ella habían podido liberarse de dos de las plagas más molestas del sistema feudal: la criminalidad de la chusma hambrienta y la arbitrariedad de los señores. Pero, andando los años y conforme se iban olvidando las antiguas calamidades, se fue haciendo cada vez más incómodo el peso del yugo policial y más palpable la doblez de sus objetivos ${ }^{53}$.

Con independencia del malestar señalado, que culminaría con la reducción del concepto a la mera protección del orden público ${ }^{54}$ y el estallido de una revolución en Francia, la teoría de la ciencia de la policía iba encaminada a mostrar la presencia de un derecho administrativo que respondía a la necesidad del contexto social y estatal de desarrollar normas de gobernancia que asegurasen, junto con el modelo estatal, "el buen orden o interés de un bien público, que legitima al Estado para actuar en cualquier orden de $\operatorname{cosas}^{\prime \prime 55}$. Siguiendo esta línea argumentativa, una vez verificados esos elementos, se podrá afirmar la existencia de la ciencia de la policía, no entendida como el fenómeno cameral, sino como fenómeno objetivo de los "Estados" semejantes al Estado absoluto moderno, que se originaba, más que en concepciones de una época específica, en necesidades de la sociedad que trascendían el tiempo, y que por tanto están presentes en cualquier momento o Estado que cumpla con la organización y concentración de poder necesarios; así se verá, entonces, en el caso romano,

52 "La policía se constituyó en el instrumento en manos del monarca para expandir su poder absoluto frente a los estamentos. La pax pública devendrá de esta manera la razón de ser de la ciencia de la policía y del Estado absoluto": ibíd., p. 154

53 Nieto García, ob. cit., p. 47.

54 "Sus fines quedan reducidos automáticamente a la prevención de la criminalidad o, más concretamente, a la garantía de la seguridad pública y del orden": NiETO GARCía, ob. cit., p. 48. O, en términos más modernos, "condiciones constituidas por la tranquilidad, seguridad y salubridad que deben existir en toda comunidad para su buena marcha": RODRíGUEZ RODRÍGUEZ, Derecho administrativo general y colombiano. 19. ${ }^{a}$ ed., Bogotá: Temis, 2015, p. 698. 
el cual no solo suplía sus necesidades de este tipo, sino que además tenía un cuerpo normativo para regular estas relaciones con la cosa pública.

\section{b. Servicio público}

"La teoría del servicio público tuvo como finalidad, al momento de platearse, ser el único sustento jurídico capaz de justificar la procedencia de un derecho administrativo. Se funda en una concepción del Estado cuya finalidad última es la prestación de servicios ${ }^{\prime \prime 56}$. Tuvo nacimiento formal en Francia, específicamente en la escuela de Burdeaux ${ }^{57}$ (a comienzos del siglo XX), donde varios doctrinantes, en un trabajo individual y singular (cada uno desde su postura y disciplina), siguieron un mismo sentido, el de justificar un derecho administrativo hasta ahora justificado únicamente en la doctrina imperante de la "puissance publique"58.

Varios teóricos, entre los que se resalta al constitucionalista León Duguit y al administrativista Gaston Jèze, coinciden en identificar al servicio público como aspecto primordial del Estado (en especial Duguit, quien no desarrolló plenamente la teoría desde el ámbito administrativo) y piedra angular del Estado de derecho, y más del derecho administrativo (desarrollado por Jèze, quien sí analizó la teoría desde un ámbito más positivista y jurídico-administrativista).

56 Alberto Montaña Plata, Fundamentos de derecho administrativo. Bogotá: Universidad Externado de Colombia, 2010, p. 48.

57 En verdad se trata del movimiento teórico francés de un grupo de doctrinantes sin conexión alguna; la influencia teórica se vio principalmente motivada por los trabajos de un grupo de estudiosos: Duguit, Jèze, Roland y Bornard, a quienes se les conoció con dicho nombre: escuela de los servicios públicos; incluso se les llamó escuela realista del derecho administrativo.

58 Esta teoría, más conocida como "teoría de las prerrogativas públicas", se sustenta y justifica con base en la necesaria utilización y efectivo ejercicio de prerrogativas por parte de algunos sujetos de derecho (normalmente de derecho público, aunque con el advenimiento del Estado de Bienestar, y unido al crecimiento de los pueblos, se empezó a ver, en la práctica, prerrogativas en cabeza de particulares -eso sí, particulares prestadores de servicios-). Se convierte entonces en una justificación que permite imponerse, legítimamente, a algunos sujetos frente a otros. Eso, en sí mismo, justifica la existencia del derecho administrativo. Es relevante tener en cuenta lo que Montaña Plata afirma acerca de esta teoría: "en términos estrictos, la connotación objetiva de esta justificación no nace de la identificación de una actividad o unas actividades precisas que merecen ser regladas por el derecho administrativo, sino, más bien, de una forma de actuar que se justifica por la existencia misma del Estado y que se materializa a través de la imposición legítima de normas que pueden tener unos sujetos sobre otros en el curso de sus relaciones" (ob. cit., p. 45). Así mismo dice este autor: "Finalmente, luego del advenimiento del arrêt BLANCO (1873), dicha teoría se ligó mucho al servicio público y se vio un paralelo entre la prerrogativa pública, sustentada en un servicio público, que da lugar a un derecho administrativo (se logra una ecuación: puissance publique = service public = droit administatif)": MONTAÑA PLATA, El concepto de servicio público, Bogotá: Universidad Externado de Colombia, 2008, pp. 131 ss. 
El concepto que desarrollarán, tendrá a partir del siglo XIX un rol primordial en toda apreciación teórica referida al derecho administrativo.

Resulta pertinente citar al respecto a Montaña Plata:

Esta idea de Estado llevada a un plano jurídico administrativo, implicaba que éste resultaba procedente (el régimen especial) en cuanto era un régimen idóneo para permitir la prestación armónica de unos servicios que se orientaban, entre otros, por los principios de igualdad, permanencia y continuidad. Los servicios públicos no tenían un alcance restringido ni similar a la consideración actual para la escuela de Burdeos, eran en cambio, el concepto totalizador de las finalidades públicas que demandaba la construcción de un régimen jurídico distinto al derecho común ${ }^{59}$.

Pues bien, esta doctrina cambia por completo la teoría administrativa para el siglo XX, modificando principalmente la concepción del Estado: el Estado es concebido como un sujeto de derecho que tiene correspondencia con los ciudadanos, pero estos dejan de concebir a aquel como un simple soberano que actúa por medio de prerrogativas, pasando a verlo y entenderlo ahora como el ejecutor de la voluntad de todos ${ }^{60}$. Partiendo de esta base, tendrá entonces el Estado que cumplir una gran labor de organización y cooperación en la prestación de servicios públicos a la comunidad, en especial por su posición especial que le permite, a él y solo a él, prestarlos eficientemente; además de ser la institución organizadora de la sociedad establecida en el "contrato social", $^{\prime \prime}$ si se quiere ver de este modo ${ }^{61}$.

El principal doctrinante de esta teoría, el constitucionalista Duguit -a quien se le atribuye una nueva concepción del Estado con fundamento en el cambio de rol de este, al pasar de ser una estructura detentadora del poder a ser una estructura puesta al servicio de los coasociados (como ya se mostró)-, definió y determinó el servicio público, diciendo que este se consolida como "la ac-

60 "La voluntad ciudadana se traduce en unos propósitos de bienestar social que no solo dan sustento y motivación a las actuaciones concretas del Estado, sino también a toda

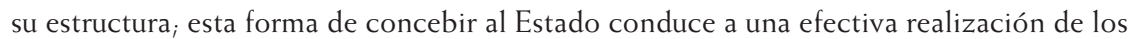
principios democráticos, aspecto éste que desde una perspectiva teórica no representa novedad alguna, pero como idea de realización concreta de estos presupuestos constituye toda una renovación para la época (nueva postura filosófica y política), pues implica una reestructuración global del rol del Estado": MONTAÑa PLATA, El concepto de servicio público, cit., p. 144. Recuérdense pues aquellas teorías de la ciencia de la policía donde el monarca igualmente actuaba en busca del bienestar de todos, pero el sustento filosófico no estaba dado por el carácter democrático del interés general ni mucho menos representaba dicha búsqueda una justificación al monarca.

61 "Se desprende para los 'gobernantes' una misión concreta que está determinada por esas finalidades del servicio público, ampliamente legitimadas por el sentir popular y llevadas a la normatividad (especial)": ibíd., p. 145. 
tividad en la cual su cumplimiento debe estar asegurado por los gobernantes, porque es tal su naturaleza que sólo puede ser realizada completamente por la intervención de la fuerza gobernante" (trad. libre) ${ }^{62}$. Sin embargo, Duguit no fue quien desarrolló plenamente la teoría en el ámbito administrativo propiamente dicho ${ }^{63}$, pues es posteriormente cuando se ve complementada dicha concepción política (Duguit planteó una posición desde el derecho constitucional, que llevó al replanteamiento del Estado imperante en la época), con repercusiones estrictamente jurídico-administrativas, lo cual fue efectivamente desarrollado por Jèze, Rolland, Bonnard y Réglade, pertenecientes a la "escuela de los servicios públicos".

Jèze, por su parte, consolida teóricamente el carácter esencial del derecho administrativo, verificando la normatividad que tiene como fundamento y objeto la idea de servicio público. En palabras de Montaña Plata, "lo que hace especial al derecho administrativo es su referencia a la noción y alcances del servicio público ${ }^{\prime \prime 6}$. Por otra parte, Rolland, viendo la necesidad de erigir unas reglas o principios básicos de la actuación administrativa, y siendo imposible la sistematización y mención específica de todas las clases de acciones que deben ejercer la administración y los prestadores de servicios, construyó unos principios de alcance general aplicables a los servicios públicos. En el derecho francés se les llama "lois de Rolland" o "lois du service public" y obedecen, más que a una construcción meramente teórica, a una elaboración con base en la realidad. Para Rolland, serán principios los de continuidad, adaptabilidad e igualdad.

Posteriormente otros doctrinantes complementaron dichos principios, aunque los nuevos no tuvieron tanta acogida como los primeros; son ellos los de: neutralidad (Laubadére), adecuación y proporcionalidad de los medios y fines (Latournerie), y moralidad y gratuidad (Hauriou).

Luego de esta construcción teórica, dicha postura entró en una crisis que se fundó en: 1. El nacimiento de un sector de servicios públicos que obedecía a estrictos presupuestos económicos, lo cual se asimilaba a la actividad particular $^{65}{ }_{i} 2$. La constante inserción de "normas comunes" 66 en la regulación de dicha temática, y 3. La aparición de los particulares como prestadores de ser-

62 LEÓn Duguit, Traité de droit constitutionnel, t. II, París: Ancienne librairie Fontemoing. 1927, p. 61.

63 De ahí que la discusión y enfrentamiento doctrinario (entre las prerrogativas públicas teorías materiales-y los servicios públicos -teorías teleológicas- como sustentos y bases del derecho administrativo) que se dio a inicios del siglo XX fuese entablada más entre Hauriou y Jèze, que con alusión a Duguit.

64 Alberto Montaña Plata, El concepto de servicio público, cit., p. 146.

65 No todo amerita la intervención del Estado, pues hay servicios que son prestados por particulares de manera natural.

66 El problema vendría a estar constituido porque no todo lo que regula el servicio público obedece a una naturaleza especial distinta a las "normas comunes" que rigen a los particulares. 
vicios. Todo ello mostró la inconsistencia de la construcción de esta escuela: la concepción subjetiva sobre la que se había cimentado la teoría del servicio público se derrumba y da paso a un fenómeno de expansión de los sujetos que desarrollan aquellos ${ }^{67}$.

Es por esto que se acudió a la distinción entre concepción amplia y concepción estricta del servicio público. La primera está ligada a la escuela realista (en consideración al derecho administrativo), y en ese sentido "resulta por consiguiente bastante restrictiva de la realidad, pues no logra definir ni dar explicación a toda la fenomenología de la administración pública, ni mucho menos caracterizar el derecho especial que le es aplicable"68. En cambio, la segunda distinción, la estricta, la cual parte de dichas consideraciones, abandona las pretensiones iniciales de dicha escuela, pero igualmente se relaciona con el interés general que persiguen las actuaciones de la administración pública. Representa entonces una forma de ser de la administración pública dirigida a proporcionar utilidad a los particulares, impuesto completamente por intereses públicos ${ }^{69}$.

Pese a que hoy en día no ofrece una unidad teórica ni doctrinal, esta noción de servicio público da, en gran medida, fundamento a la administración pública y al propio derecho administrativo. Eso sí, no es una construcción completa y absoluta que permita identificar por completo todo el fenómeno administrativo: la administración y su derecho ${ }^{70-71}$.

Finalmente, debemos traer a colación cuanto ha dicho la Corte Constitucional acerca del concepto en estudio:

... el concepto de servicio público ha sido objeto de un permanente desarrollo ligado a la constante evolución de la situación política, económica y social del mismo Estado. En el momento actual, no ha presentado una modalidad estática, sino cambiante y adaptable a la praxis económica y social, así como consecuente con el permanente avance de sus contenidos, entendiéndose el mismo, en el

67 Fenómeno que Roma ya había vivido y que solucionó de una manera formidable, como se verá en líneas siguientes.

68 Montaña Plata, El concepto de servicio público, cit., p. 156.

69 En este sentido, GARRIDO FALLA, Tratado de derecho administrativom t. II. Madrid: Tecnos, 1994, citado ibíd., p. 156

70 "En buena medida da una razón finalista o teleológica de la administración pública y por consiguiente, del derecho administrativo": ibíd., p. 158.

71 De la misma manera, el interés general constituye hoy en día un elemento buscado en las actividades propias de la administración pública, y aunque no logra, al igual que la teoría del servicio público, explicar e identificar por completo el derecho administrativo ni construir el objeto absoluto de la administración, sí les da una orientación determinante en una realidad caracterizada por una normatividad a la que se le reconoce su especialidad (sin que sea posible atribuirle un criterio objetivo preciso) y por un derecho administrativo en el que su normatividad especial no resulta suficiente para regular las complejas relaciones actuales. 
ámbito jurisprudencial y doctrinario, como aquellas actividades que el Estado tiene el deber de prestar a todos los habitantes del territorio nacional, de manera eficiente, regular y continua, en igualdad de condiciones, en forma directa, o mediante el concurso de los particulares, con el propósito de satisfacer las necesidades de interés general que la sociedad demanda ${ }^{72}$.

\section{c. El derecho administrativo romano}

La historia ha mostrado que el ser humano necesita agruparse para sobrevivir la existencia del individuo presupone una sociedad, la cual a su vez necesita de normas que aseguren su permanencia y bienestar, normas que en principio son sociales o religiosas, sacras, pero que con el avance de la civilización terminan traduciéndose en normas jurídicas, reglas imperativas que rigen las relaciones entre individuos, pero también las relaciones entre el individuo y la colectividad. La experiencia romana no fue ajena a tal desarrollo; ampliamente conocido es de todos el sistema jurídico ideado por los romanos, aunque también es común relegar tal desarrollo únicamente a los ámbitos del derecho privado, pues se ignora que, como civilización, Roma también gozó de un sistema de administración y manejo de lo que se entendía primigeniamente como la res publica, adoptando un sistema que, de traerse a la actualidad, mostraría que desarrolla las temáticas y problemáticas propias de la administración y del derecho administrativo actuales ${ }^{73}$.

Si bien es cierto que en Roma no hubo un desarrollo teórico exhaustivo de una ciencia del derecho administrativo ${ }^{74}$, "los casos de la jurisprudencia y

72 Corte Constitucional, Sentencia C-075 de 1997, M.P.: Hernando Herrera.

73 "Si bien es evidente la influencia que la Revolución francesa tuvo en los sistemas jurídicos y políticos de la cultura occidental, lo que en el caso del derecho administrativo se manifestó en la teorización que originó la ciencia del derecho administrativo y en la elaboración de códigos unitarios y autónomos de derecho administrativo, no parece acertada, sin embargo, la opinión de que el derecho administrativo moderno surge en el siglo XIX. Tal afirmación se debe, en parte, a la ausencia de una reconstrucción dogmática del derecho administrativo romano. La problemática correspondiente a la administración ciudadana romana espera todavía ser estudiada en profundidad, y no solo por un mero interés histórico, sino para conocer mejor el ordenamiento jurídico contemporáneo, que en buena medida es tributario de instituciones, hechos y actividad de orden administrativo que fueron conocidos y regulados en el ámbito estatal, provincial y municipal de la comunicad política romana. [...] [E]xiste en el ámbito del derecho administrativo, continuidad histórica e interdependencia": FERNÁNDEZ DE BUJÁN, ob. cit., p. 181.

74 Sin embargo, KOSCHAKER, en Europa y el derecho romano (1947), citado por FERNÁNDEZ DE BujÁN (ob. cit.), dice que lo único que falta es "construir una historia de los conceptos y de los dogmas del derecho público romano, realizada dogmáticamente y con un método histórico, es decir, con las modernas técnicas de la ciencia del derecho". 
la compleja estructura administrativa nos permiten afirmar la existencia de un Derecho administrativo romano" $175-76$

Antes de empezar a exponer la experiencia romana es necesario plantear la diferenciación doctrinal realizada por Giannini entre organización administrativa, derecho administrativo y las categorías de ciencia del derecho administrativo. La primera será entendida como la estructuración del aparato estatal que desarrollara toda una serie de actividades, pues, en definitiva, "todos los ordenamientos jurídicos, incluso los más simples, tienen una estructura u organización administrativas ${ }^{1177-78}$; por lo segundo se entenderá el debido establecimiento de un aparato administrativo complejo integrado por instituciones, hechos y actividades de orden administrativo; y finalmente, por lo último se entenderá aquella labor especulativa que se realiza de manera general respecto de las instituciones y de la propia actividad administrativa ${ }^{79}$.

Fernández de Buján cita a Ángel Latorre, quien El valor actual del derecho romano escribió que "podemos hablar de una administración en Roma y de un derecho administrativo en sentido amplio [pues] hasta encontramos en el digesto problemas de carácter administrativo que ofrecen una solución de sorprendente modernidad", y de la misma manera, reconoce que "lo que no existe en Roma, ni referida al derecho romano, es una ciencia del derecho administrativo, en cuanto no fue objeto de dicha especulación teórica general por parte de los juristas romanos ${ }^{1180-81}$.

75 ESTHER PENDÓn MELÉNDEZ, Régimen jurídico de la prestación de servicios públicos en derecho romano, Madrid: Dykinson, 2002, p. 26.

76 Como se ha intentado mostrar a través del presente escrito, el derecho romano tenía una problemática compleja administrativa "en las que se encuentran planteadas y satisfactoriamente resueltas las grandes cuestiones teóricas y prácticas del derecho administrativo actual, como: bienes patrimoniales y públicos, disponibles o no disponibles, obras públicas, concesiones y autorizaciones, servicios públicos prestados por sociedades privadas, justicia penal y administrativa, orden público, policía social e higiénica, práctica religiosa, relaciones con la administración central", entre otras materias: FERNÁNDEZ DE BUJÁN, ob. cit., p. 182. El mismo autor cita a IMPALLOMENI, quien había rescatado ya algunos temas que fueron de amplio desarrollo romano (p. ej., responsabilidad administrativa, saneamiento financiero, organización de la burocracia estatal, privilegios de la administración) y que tienen una continuidad histórica en el planteamiento de las cuestiones, cuya resolución se aborda en el derecho romano mediante soluciones de sorprendente modernidad.

77 Ibíd., p. 185.

78 Desarrollo que se encuentra "integrado por instituciones, hechos y actividades de orden administrativo, lo que en el caso de Roma se produce en un nivel de desarrollo semejante a la importancia histórica y al grado de expansión de su comunidad política": ibíd., pp. $185-186$.

79 Montaña Plata, Fundamentos de derecho administrativo, cit., pp. 24-25.

80 FERNÁNDEZ DE BujÁN, ob. cit., p. 186.

81 Sin embargo, algunos romanistas sí ven una especie de desarrollo por los juristas de dicha temática administrativa, pero no de manera exhaustiva ni de forma científica, como en 
Partiendo de lo ya expuesto, existe un derecho administrativo en Roma que se ve evidenciado fácticamente en toda la experiencia jurídica de dicha sociedad y como pleno desarrollo, de manera similar, de aquellos sustentos que hoy constituyen el objeto propio del derecho administrativo y/o desarrollo de las posturas teleológicas ya estudiadas ${ }^{82}$. Además, al ser este un derecho, en principio, jurisprudencial ${ }^{83}$, podemos evidenciar unos antecedentes de la creación de una ciencia del derecho administrativo: como Riccobono reconoce, "ya en las fuentes clásicas existe una actividad científica de los juristas dirigida a aclarar y sistematizar conceptos e instituciones propios de la materia" ${ }^{184}$.

Una vez se tiene un sistema estatal consolidado como el romano, es normal que este se encargue de estructurarse a sí mismo a partir del contexto, según los requerimientos y problemáticas a los que se enfrente, para asegurar su permanencia y la correcta administración, se debe velar entonces por el orden público, por la prestación de servicios públicos y el desarrollo de la infraestructura, para esto se necesita no solo de instituciones consolidadas, sino también de la existencia de un personal humano que sea el que desarrolle las funciones que de manera abstracta se le atribuyen al "Estado".

Al comienzo del Digesto de Justiniano es apreciable que para los juristas de la época no era extraño el concepto de derecho público ${ }^{85}$; desde una edad temprana la cultura romana empezó a organizarse mediante la figura de las magistraturas para suplir las necesidades de la administración y si,

líneas siguientes se expondrá. En este sentido, RICCOBONO, citado por FERNÁNDEZ DE BuJÁN, ob. cit.

82 Claramente se ve en Roma un desarrollo normativo orientado a la eficiente prestación de servicios públicos, los cuales iban dirigidos a satisfacer a la sociedad y brindar las condiciones necesarias para mantener y desarrollar la amplitud del Imperio por todo el mundo conocido. De la misma manera, como una especie de desarrollo de lo que llegaríamos a llamar "ciencias de la policía", en Roma se estructuró la burocracia necesaria para mantener el orden y satisfacer necesidades en la ciudad, que, como también se verá en las líneas siguientes, se dio con la creación de un jefe de policía de la ciudad, que vino a remplazar al antiguo prefecto de la ciudad.

83 Basta ver el Digesto (principal cuerpo normativo romano) como compilación de opiniones de los juristas, que eran, en un inicio, simples ciudadanos conocedores del ius, y posteriormente se acercarían más al príncipe y derivarían su auctoritas del ius publice respondendi ex auctoritate principis, para finalmente, desde la época de Trajano, terminar asumiendo el papel de consejeros permanentes y remunerados. Vid. EsPITIA GARZÓn, Historia del derecho romano, cit.

84 Citado por FERNÁNDEZ DE BUjÁN, ob. cit., p. 186. Afirmación no del todo compartida por la romanística actual.

85 D. 1.1.1.2: Ulpiano, Instituciones, libro I: "Dos son los aspectos de este estudio, el público y el privado. Es de derecho público, el que se refiere al estado de la cosa romana; privado, el que á la utilidad de cada individuo; pues unas cosas son útiles pública, y otras privadamente. El derecho público consiste en las cosas sagradas, las de los sacerdotes, y las de los magistrados. El derecho privado consta de tres partes, pues está compuesto de los precepto naturales, ó de los de gentes, ó de los civiles". 
ciertamente, la categoría ciencia del derecho administrativo es ajena a la experiencia romana (pero como consecuencia de esa labor práctica, más que sistematizadora de los romanos), tal y como lo expresa Fernández de Buján, no lo es para la tradición romanística, la cual la usa para "referirse al ámbito de experiencia administrativa romana caracterizada por la existencia de un aparato administrativo de compleja estructura integrado por instituciones, hechos y actividad de orden administrativo en el ámbito estatal, provincial y municipal, que intenta resolver la problemática que presenta una sociedad viva y en constante expansión y desarrollo en la que se plantean cuestiones prácticas que continúan vigentes en el momento actual" ${ }^{\prime \prime 6}$.

Para comenzar hay que hacer una breve alusión a la noción que tuvo el derecho romano sobre lo público, para lo cual necesitamos acudir a la figura del fisco, que se entendía como el centro de toda la gestión económica del Imperio, el cual además tenía personalidad jurídica ${ }^{87}$; si bien este, en un principio, estaba diferenciado del patrimonio del príncipe ${ }^{88}$, con el desarrollo del principado terminaron fundiéndose estas figuras ${ }^{89}$, quedando entonces un patrimonio a nombre del príncipe, sujeto al desarrollo de todas las obras públicas, contratos y prestación de los servicios, sin dejar de lado que a nivel municipal existía un aerarium o "fisco propio", el cual también llevaba a cabo obras en interés de la comunidad $^{90-91}$. A partir de aquí procedemos a exponer ciertas instituciones romanas que permiten aproximarse al derecho administrativo romano.

\section{ESTRUCTURA ADMINISTRATIVA}

Tal y como se dijo con anterioridad, los romanos desde época temprana empezaron a diseñar una estructura administrativa que giraba en torno a la necesidad práctica de mantener el Imperio y expandirlo como fuera, a la vez que preten-

86 FeRnANDÉZ DE BujÁN, "Hacia un tratado de derecho administrativo romano", Revista de Derecho UNED, n. ${ }^{\circ}$ 6, 2010, pp. 207-208

87 Penagos, ob. cit., p. 9.

88 Así Pimiento, siguiendo a Laureano López Rodó, señala: "De un lado, existían los comicios y las magistraturas republicanas bajo tutela del Senado, las provincias senatoriales, el erario del pueblo romano (aerarium publicum) administrado como antes (época de la República). Del otro, el príncipe con sus funcionarios, las provincias imperiales, el fiscus Caesaris, la soberanía del príncipe": Julián PIMIENTO ECHEVERRY, Derecho administrativo de bienes. Los bienes públicos: bistoria, clasificación, régimen jurídico, Bogotá: Universidad Externado de Colombia, 2015, p. 89.

89 MOMMSEN, ob. cit., p. 380

90 Penagos, ob. cit., p. 9.

91 En la construcción de vías públicas es interesante cómo se manejaba una participación de los entes locales junto con aportes de privados, del aerarium (cuando era diferenciable) y el patrimonio del príncipe. Vid. VANESA PONTE, "La regulación de las vías públicas en el seno del derecho administrativo romano", Hacia un derecho administrativo y fiscal romano, ANTONIO FERnÁNDEZ DE BuJÁN (coed.) Madrid: Dykinson, 2011. 
dían mantener las ciencias camerales del Estado absoluto. Sin duda alguna la estructura pública romana, aunque abandonada en el estudio jurídico y dejada a los meros historiadores del derecho ${ }^{92}$, es el sustento de las administraciones posteriores a su caída, e incluso, como varios autores reconocen, de algunas administraciones modernas que se jactan de independientes y autónomas, pero que obedecen a la misma temática romana y a algunas de las instituciones más importantes de dicha construcción pública ${ }^{93}$.

Sin embargo, teniendo en cuenta la necesidad del estudio detallado de las instituciones romanas como un mecanismo idóneo para mejorar y complementar la teoría actual de la administración, y de la misma manera, requiriéndose la adecuada estructuración de un sistema que responda a las necesidades del grupo en un momento determinado, es el mismísimo Mommsen, gran historiador y doctrinante del derecho romano, quien da la primera muestra clara, precisa y detallada de lo que fue la estructura pública romana como una creación evolutiva que obedecía al tránsito que hacía Roma en sus modelos de organización estatal (de la Monarquía hasta el Dominado). Este doctrinante desarrolla de manera completa la estructuración de ese derecho público, analizando cada uno de los cargos y organismos que los romanos creaban para solucionar sus problemáticas, tan complejas como las actuales ${ }^{94}$.

A su turno, Fernández de Buján desarrolla un estudio amplio al respecto, pero diferenciando de mejor manera las distintas manifestaciones de la admi-

92 "La vigencia en la práctica del derecho privado romano hasta la entrada vigor en el año 1900 del código civil alemán, su consideración general como modelo abstracto de sistema jurídico y su influencia directa en el derecho europeo a través del derecho común, la pandectística y las codificaciones, a causa del valor intrínseco de las soluciones jurídicas creadas por Roma, supuso el estudio y reconocimiento de aquél con carácter obligatorio en la gran mayoría de las universidades europeas hasta nuestros días, pero supuso, en contraposición, una relegación del estudio del derecho público romano. Sin embargo, la justificación del estudio de este último se fundamenta en la unidad lógica del ordenamiento jurídico y en la convicción de que no cabe explicar la norma jurídica al margen de las distintas circunstancias políticas, económicas, sociales o religiosas que operan en una comunidad": ANTONIO FERNÁNDEZ DE BuJÁN, Derecho público romano. 2. ${ }^{a}$ ed. Madrid: Civitas, 1997, pp. 21-22. En parte, podría decirse que dicha relegación al estudio del derecho público romano y su administración se dio por el intento de rechazar antiguos regímenes que no se vieran reflejados y estructurados a partir de teorías actuales, como las de libertad, igualdad y demás postureas filosóficas y políticas. Se debe decir que la Edad Media intentó, en gran parte, rechazar todo lo logrado por la Edad Antigua y, de manera similar, la Edad Moderna intenta rechazar los postulados de los medievales. Solo algunos estudiosos querrán abstraer de cada una de las etapas del desarrollo aspectos positivos y con ello conocer y estructurar un mejor futuro.

93 En este sentido, PenaGos, ob. cit., pp. 21 ss.

94 Mommsen, ob. cit., pp. 314 ss. Y es principalmente en el Principado y el Dominado que vamos a encontrar un desarrollo más exhaustivo sobre la temática administrativa. 
nistración romana. Por ello, expondremos algunos de sus puntos de manera breve ${ }^{95}$ :

a. Nueva organización administrativa frente a los nuevos territorios conquistados: a partir de la expansión por suelos no itálicos, especialmente con la conquista de Sicilia, los romanos vieron la necesidad de encuadrar su antigua estructura, sustentada en un grupo cerrado y pequeño que ya había empezado a expandirse, para poder dar paso al control sobre el Mediterráneo, África, Asia y casi todo lo que hoy constituye Europa. Se vieron obligados a estructurar y regular la nueva realidad de las relaciones entre la metrópoli y las nuevas comunidades. Efectivamente es con Sicilia y Cerdeña que Roma inaugura el sistema provincial, dando regulaciones específicas a cada una de ellas por medio de la lex provincia. Cabe ver en el desarrollo romano, en su estructuración de las provincias y localidades, un claro antecedente de la organización administrativa que se utiliza hoy en día en los países para dar desarrollo a las municipalidades, departamentos y regiones.

b. Sujetos y destinatarios de los actos administrativos: es a partir del Principado que empieza a surgir un concepto de funcionario, aunque no distinguible bajo ese término, pues tenían nombres específicos: praefecti, curatore, aedilis, entre otros; se trataba del personal que desarrollaba una actividad pública, que bien podía ser desarrollada o en la cancillería imperial o bien en los distintos entes provinciales o locales. Aquellos funcionarios eran titulares de un régimen especial, sometido fuertemente a estructuras jerárquicas, como consecuente desarrollo de una especie de carrera administrativa.

Podemos analizar, por ejemplo, dos clases de funcionarios romanos: por un lado, las construcciones dentro de la ciudad y el mantenimiento y desarrollo de las vías y carreteras itálicas fueron atribuidos a curadores; así para los edificios urbanos, para los acueductos urbanos, para las cloacas urbanas e incluso para el río Tíber. Por otro lado, tenemos al jefe de policía de la capital, que vino a remplazar al antiguo prefecto de la ciudad, pero con mayores atribuciones. Este nuevo funcionario fue tomando conocimiento, poco a poco, de los negocios criminales de la capital, y con el tiempo llegó a ponerse a la cabeza de toda la administración urbana.

Hoy en día, en la enseñanza del derecho administrativo, se suele dividir su estudio en tres partes: a. parte introductoria o de "nociones generales"; $b$. parte estática o "estructura propia de la administración pública", y c. parte dinámica 
o propiamente llamada "actuación administrativa"96. Es en la segunda donde se enmarca este breve análisis y, aunque el simple reconocimiento de un sujeto público administrativo (lo cual es algo meramente formal) no da sustento inequívoco a un derecho administrativo plenamente consolidado y distintivo, sí da muestras del fenómeno romano: la creación de toda clase de función y órgano requerido para ser encargado de realizar actividades de gestión, seguridad, abastecimiento, cuidado, salubridad, entre otras cuestiones. Y debe tenerse en cuenta una evolución interesante del derecho romano: se reconoció la potestad de realizar dichas actividades a sujetos particulares, privados que eran delegados por los funcionarios para la efectiva realización de un fin concreto, como ya veremos.

\section{Prestación de SeRvicios públicos}

Resulta especialmente extraña la utilización del término "servicio público" en el derecho anterior al siglo XIX, y sin embargo la experiencia romana presenta una regulación ante tal necesidad y creó figuras jurídicas para su correcta prestación. Al respecto, se debe estudiar en primer lugar la figura de las sociedades de publicanos (societas publicanorum), un tipo de sociedades que tienen un régimen especial y se encargan de, mediando una concesión por parte de la administración, prestar diferentes servicios.

Etimológicamente el término publicanus se refiere en un inicio al arrendador de impuestos públicos, los arrendatarios del vectigal, que era un impuesto por la utilización del ager publicus ${ }^{97}$, cuyo valor de recaudo permitiría el uso de lo público, y es así como se fueron asemejando los términos publicum y vectigal98; con el desarrollo de la administración romana el concepto se fue ampliando y terminó abarcando cualquier adjudicación hecha en Roma por la administración a los particulares ${ }^{99}$. Así cabe citar a Ulpiano (D. 39.4.1.1), quien ofrece

96 La actuación administrativa viene a ser el objeto primordial del derecho administrativo; ella da sustento a la existencia de una parte estática, lo que se fundamenta en bases teleológicas que atiendan a los fines deseados por el grupo. En este sentido, JOSÉ J. SÁNCHEZ GONZÁLEZ, La administración pública como ciencia: su objeto y su estudio. México D.F.: Instituto de Administración Pública del Estado de México y Plaza y Valdés. 2001, pp. 253 ss.

97 "Cierta suma de dinero (vectigal) como arrendamiento censorio": ESPITIA GARZÓN, ob. cit. p. 86.

98 "De esta forma, comenzaba a originarse una nueva concepción que entendía que debía pagarse determinada cantidad por la utilización de lo que se consideraba público, es decir el vectigal, concepto éste que podría ser expresado bajo la denominación de publicum, y de este modo parece justificarse el hecho de que en las fuentes, vectigal y publicum se utilicen en ocasiones como sinónimos": PENDÓn MELÉnDEZ, ob. cit., p. 32.

99 "La amplificación del término y el paso a su sentido extenso es primero simple consecuencia de la mayor complejidad de la hacienda romana. Cuando los ingresos por impuestos no se referían fundamental y casi exclusivamente a las parcelas agrícolas del ager publicus, sino a la utilización de puertos, caminos, puentes, etc., o se basaban en la importación 
una aproximación a la categoría de los publicanos: "Este título se refiere á los publicanos. Mas son publicanos los que disfrutan de tributos públicos; porque de esto reciben el nombre, ya paguen el tributo al fisco, ya perciban para sí el tributo; y todos los que toman del fisco alguna cosa en arrendamiento se llaman con razón publicanos".

Ahora, con respecto al especial régimen que tenían, ha de aclararse en primer lugar que el contrato de sociedad en Roma era consensual, oneroso y de buena fe, que consistía en dos o más personas que, mediando aportes, iban juntamente en sociedad (coire in societam) para realizar un fin común y así obtener utilidades que serían repartidas equitativamente ${ }^{100}$ i es necesario resaltar que, al contrario que en la actualidad, no se constituía una persona jurídica como consecuencia del contrato; sin embargo, en esta "especie" de sociedad la doctrina afirma que era posible la adquisición de personalidad jurídica, lo cual "significaba para la societas el privilegio de ser considerada un ente individual sujeto de derechos y obligaciones, independiente de las personas físicas que la integraban"101, siempre y cuando mediara una previa autorización ${ }^{102}$, la cual debía provenir de un senadoconsulto, una ley o una constitución imperial ${ }^{103}$.

Además de lo anterior también contaban con una estructura diferenciada en la cual se distinguen: a) órganos directivos y de representación, b) fiadores, c) soci ordinario, d) adfines y e) empleados subalternos ${ }^{104} ;$ y existían unos mecanismos especiales de administración ${ }^{105}$ y disolución ${ }^{106}$.

o exportación de mercancías, aunque tales ingresos recibieran a veces denominaciones específicas -solarium, scriptura, cloacarium, portorium-, la denominación de los particulares concesionarios o arrendatarios continuó derivándose de la genérica expresión que servía antiguamente para el impuesto publicum; y se siguió llamándoles publicani. [...] La extensión del significado no paró ahí. Se llamó también publicani a los concesionarios de obras, trabajos o suministros, porque publica servía -en acepción que MOMMSEN llama impropia o incorrecta- para designar los aprovisionamientos contratados por el Estado por el sistema de arriendo, los denominados ultro tributo": JUAN ANTONIO ARIAS BONET, "Societas publicanorum", Anuario de Historia del Derecho Español, Madrid: Boletín Oficial del Estado, n. ${ }^{\circ} 19,1948-1949$, pp. 220-221.

100 Alejandro, Guzmán Brito, Derecho privado romano, t. II, Santiago: Jurídica de Chile, 2004 pp. $175-176$.

101 Pendón MelÉndeZ, ob. cit., p. 43.

102 Ibíd., p. 44.

103 D. 3.4.1, pr. (Gayo, Comentarios al edicto provincial): "no se concede indistintamente a todos que se constituya sociedad ni colegio ni otra corporación semejante; porque esto está restringido por leyes, senadoconsultos y constituciones de los príncipes. Para muy pocas cosas se han permitido semejantes corporaciones, como por ejemplo, se permitió formar cuerpo a los consorcios arrendatarios de las contribuciones públicas, o de minas de oro, o de plata, o de salinas. [...]".

104 En este sentido, ARIAS BONET expone claramente las funciones de cada uno de los integrantes de las sociedades de publicanos. Vid. ARIAS BONET, ob. cit., pp. 254 ss.

105 Ibíd., p. 271.

106 Pendón MelÉNDEZ, ob. cit., p. 48. 
Los municipios y/o el aerarium se encargaban de llevar a cabo, según las reglas de gobernancia (muy semejantes a la ciencia de la policía), diferentes obras para el bienestar del pueblo, pero no siempre eran estos los que lideraban tales obras; es por esto que se acudía, así como en la actualidad, a contratistas privados para la prestación de tal servicio, sin dejar de lado la posibilidad de que el "Estado" se hiciera cargo de tal prestación ${ }^{107}$; si ciertamente no había un cuerpo global que regulara la concesión administrativa, sí había:

... un amplio elenco de interdictos dirigidos a la defensa de los concesionarios públicos; existe un riguroso y formal procedimiento previo a la concesión; los concesionarios se adhieren, en su caso, a unos minuciosos pliegos de condiciones, en los que se recogen aspectos referidos al carácter temporal o perpetuo de la concesión, las facultades y obligaciones del concedente y concesionario, las modalidades de pago del canon o vectigal, las eventuales garantías a prestar por el concesionario y los controles a realizar por parte del ente público concedente ${ }^{108}$.

En razón de esto podemos concluir que en un "Estado" como el romano existió la necesidad de satisfacer intereses generales, lo que motivó la creación jurídica de mecanismos que facilitaran la prestación de servicios públicos, y que de esta forma se pudieran llevar a cabo actuaciones administrativas como recaudaciones de impuestos, concesiones de minas, construcciones de acueductos, caminos, obras públicas en general, entre otras.

\section{CONSIDERACIONES FINALES}

Por medio del examen adelantado en el presente artículo se ha podido constatar que, en primer lugar, el derecho como fenómeno social responde a las necesidades del grupo, y que por tanto estructura diferentes figuras e instituciones

107 Al respecto, FERNÁNDEZ DE BUJÁN, siguiendo a JosÉ LUIS MURGA, señala: "Sobre prestación de servicios públicos por sociedades de particulares a través de la figura de la concesión, tiene escrito MURGA que: 'fue algo ordinario dentro de la variada administración municipal romana que el servicio público no lo ofreciera directamente la curia municipal sino que se prestara a través de un contratista-redemptor-cuya actuación debía ser siempre conforme a la lex locationis. No es raro encontrar en el Digesto frecuentes referencias a los más variados servicios públicos cedidos en arrendamiento a un redemptor, debiendo en todo caso el concesionario sujetarse al contrato con un planteamiento absolutamente privatístico' $[\ldots]$ En otras ocasiones, era la propia Administración la que prestaba el servicio público correspondiente, que en el caso de nueva creación implicaba o bien la atribución de empleados públicos a las nuevas necesidades sociales o bien la creación de cargos y empleados ex novo para el desempeño de las nuevas funciones": FERnANDÉZ DE BUJÁN, Hacia un tratado de derecho administrativo romano, cit., pp. 214-215.

108 Antonio Fernandéz de Buján, Derecho Público Romano. Ed. 2. Madrid: Civitas, 1997, pp. 189-190. 
para suplir las necesidades, en este caso, de la administración, por ello, es preciso analizar de manera histórica las instituciones de un determinado grupo, para poder entender el fenómeno de la administración a través del tiempo.

Es por ello que se procedió a estudiar algunas de las posturas que han intentado, de una forma u otra, reconstruir y mostrar las bases del derecho administrativo y darle sustento a su particular naturaleza especial. Dichas construcciones teóricas han ayudado a la consolidación de una ciencia del derecho administrativo; sin embargo, requiriendo un sustento finalístico y constatando en el presente estudio la insuficiencia de aquellas para señalar un origen unívoco de este derecho, en cuanto se ignoran las complejas problemáticas que se han presentado en el trascurso histórico (que le son precedentes), se hace necesario desligar los fundamentos teleológicos de aquellas posturas cronológicas (supra A.I), para poder evidenciar el fundamento estructural y esencial que corresponda a la realidad histórica y al fenómeno de la actuación administrativa (elemento que debe estar presente en todo el proceso de desarrollo que se da, desde la existencia empírica de una administración, pasando por la regulación y estructuración de un derecho administrativo, hasta la consolidación de la ciencia de este derecho) - p. ej., servicios públicos ${ }^{109}$, orden público, economía y bienestar.

Este elemento, que constituye una necesidad práctica de dar respuesta a los fenómenos sociales que una organización estatal con cierto desarrollo y amplitud en sus instituciones tiene, está expuesto en las posturas que analizamos como "teleológicas", y que según nuestra metodología es indiferente al momento histórico de creación de las mismas, por lo que se puede buscar tal desarrollo en construcciones anteriores que dan regulación a esas temáticas y que han sido punto de partida, consciente o inconscientemente, de los ordenamientos actuales. Por eso, reiteramos, ese aspecto finalista es el que da pie y es punto de partida de esa regulación jurídico-práctica llamada derecho administrativo, pues independientemente de la época en que se ubique, es la razón por la cual se idean estos mecanismos para poder suplir las necesidades de abastecimiento, seguridad, infraestructura, prestación de servicios, entre otros.

La estructuración formal del concepto de derecho administrativo y su ciencia no vendrá a darse sino con el advenimiento de la Revolución francesa y su cambio de perspectiva político-jurídica, lo que no se desconoce; sin embargo, ya en la civilización romana se evidenciaron las necesidades que son terreno de germinación del elemento esencial, que terminaron por requerir, de hecho, un derecho administrativo. Resulta inapropiado, desde esta perspectiva, desconocer los desarrollos normativos anteriores, pues aunque la Revolución

109 "Dejando de lado la inspiración jurídico filosófica con que se aprecie esta realidad, la prestación de servicios públicos ha estado presente desde los tiempos remotos en que el detentador del poder político ha desarrollado este tipo de prerrogativas": Alain-Serge Mescheriakoff, citado por MONTAÑA PlatA, ob. cit., p. 115. 
francesa cambie toda la perspectiva ideológica en su momento, el fenómeno se constata, desarrolla y normativiza previamente.

Es así como un imperio, como el que fue Roma, tenía presente este elemento como desarrollo de sus necesidades concretas, si bien, dada la falta de interés de los romanos por estructurar y definir conceptos como algo independiente y abstracto, no alcanzó el desarrollo de una ciencia compleja como la que existe hoy en día, eso sí, ya allí se planteó un sistema coherente y compuesto que pudo responder muy eficazmente a las necesidades de la época, y comparándolo con sistemas actuales, tiene sustentos similares al desarrollo de nuestra materia.

Para terminar, es preciso indicar que el estudio del derecho administrativo romano no debe dejarse relegado a los historiadores del derecho como un simple acontecimiento accidental sin mayor relevancia actual ${ }_{i}$ su investigación va más allá del mero interés ocioso, pues este sistema jurídico, que alcanzó un notable desarrollo, puede proporcionar nociones útiles para la administración y para la construcción de nuestra ciencia actual, tal y como se evidenció, problemas como el que sucedió a inicios del siglo XX, referente a la prestación de servicios públicos por particulares, ya habían sido regulados por el derecho romano ${ }^{110} ;$ así mismo, podrán ser objeto de estudio más temáticas en busca de dar solución a problemas humanos que han sido permanentes en la historia.

Los casos que enuncia este derecho pueden constituir un ejemplo y experiencia para decidir los caminos por los que se va a guiar de ahora en adelante esta bella materia. Es ésta una invitación al estudio científico del pasado, en aras de buscar una respuesta a problemáticas del futuro; y téngase presente desde ya un punto a favor de Roma y su derecho: su forma de organización política, jurídica y social vivió cerca de 1.200 años a través de la historia, lo que puede significar un buen ejemplo de cómo se pervive en el tiempo.

\section{BIBLIOGRAFÍA}

ARAujo Lobo, Alice J. "Cameralismo: un antecedente más en la evolución de la administración como ciencia", Visión Gerencial, año 14, n. ${ }^{\circ} 1$ (enero-junio), Universidad de los Andes de Venezuela. 2015, pp. 165-180.

110 "Está previsto un amplio elenco de interdictos dirigidos a la defensa de los concesionarios públicos; existe un riguroso y formal procedimiento previo a la concesión ${ }_{i}$ los concesionarios se adhieren, en su caso, a unos minuciosos pliegos de condiciones, en los que se recogen aspectos referidos al carácter temporal o perpetuo de la concesión, las facultades y obligaciones del concedente y concesionario, las modalidades de pago del canon o vectigal, las eventuales garantías a prestar por el concesionario y los controles a realizar por parte del ente público concedente": FERNANDÉZ DE BuJÁN, ob. cit., pp. 189-190. 
Arias Bonet, Juan A. "Societas publicanorum", Anuario de bistoria del derecho español, n. ${ }^{\circ}$ 19, Madrid: Boletín Oficial del Estado, 1948-1949, pp. 220-221.

BASTIDAS BÁRCENAS, Hugo. "La actividad administrativa, la funcion pública y los servicios públicos", Revista Con-texto (Revista de derecho y economía) n. ${ }^{\circ} 41$ (enerojunio), Universidad Externado de Colombia. 2014, pp. 51-65.

BlanCH Nougués, José M. Régimen jurídico de las fundaciones en derecho romano. Madrid: Dykinson. 2007.

Bobbio, Norberto y Matteucci, Nicola (dirs.). Diccionario de Política, 5. a ed., 1987, Homero Alemán, Juan Jacobo Simón y Haydée Valero (trads.), México D.F.: Siglo XXI, 1976.

Dicey, Albert. An Introduction to the Study of the Law of the Constitution. London: St. Martin's Press. 1967.

Domingo, Rafael (dir.). Textos de derecho romano. México D.F.: Thomson Aranzadi. 1998.

Duguit, LeÓn. Traité de droit constitutionnel, t. II, París: Ancienne Librairie Fontemoing, 1927.

Espitia GarZÓn, FABIO. Historia del derecho romano, 5. a ed., Bogotá. Universidad Externado de Colombia. 2016.

Fernández de Buján, Antonio. Derecho público romano. 2. ${ }^{a}$ ed., Madrid: Civitas. 1997.

FERNÁNDEZ DE BUJÁN, ANTONIO, (coed.). Hacia un derecho administrativo y fiscal romano. Madrid. Dykinson. 2011.

GARCÍA DE ENTERRÍA, EdUARDO. Dos estudios sobre la usucapión en derecho administrativo, 3. a ed., Madrid: Civitas. 1998.

García de Enterría, EduARDo. La lengua de los derechos. La formación del derecho público europeo tras la Revolución francesa, Madrid: Alianza, 1994.

GARRIDO FALla, FERnANDO. "El concepto de servicio público en el derecho español", Revista de Administración Pública, n. ${ }^{\circ} 135$ (septiembre-diciembre), Madrid, 1994.

GonZÁlez de CAnCino, EMILSSEn. Manual de derecho romano, 6. ${ }^{a}$ ed., Bogotá: Universidad Externado de Colombia, 2007.

Guerrero Orozco, Ómar. Teoría administrativa del Estado. México D.F.: Oxford University Press. 2000. 
Guerrero Orozco, Ómar. "Las Ciencias Camerales", Revista Ensayos, vol. II, n. ${ }^{\circ} 6$, Universidad Nacional Autónoma de México, 1985, pp. 16-20.

Guerrero Orozco, Ómar. "Los Estados Monásticos: Una experiencia administrativa medieval", Revista del Seminario de Cultura Mexicana, primera época, año 5. n. ${ }^{\circ} 8$ (septiembre), 2015, pp. 89-112.

Guerrero Orozco, Ómar. "Von Justi y la ciencia de la policía. Retrospección y prospectiva", en Memorias Segundo Congreso Internacional de Ciencia de Policía, Bogotá, octubre de 2011, pp. 53-64.

GuZmán Brito, Alejandro. Derecho privado romano, Santiago de Chile: Jurídica de Chile, 2004.

Hernández BeCERra, Augusto. Las ideas políticas en la bistoria. Bogotá: Universidad Externado de Colombia, 2001.

Malagón Pinzón, Miguel. Vivir en policía: una contralectura de los orígenes del derecho administrativo colombiano. Bogotá: Universidad Externado de Colombia, 2007.

Malagón Pinzón, Miguel. "La ciencia de la policía y el derecho administrativo", Revista Estudios Socio jurídicos, vol. 6, n. ${ }^{\circ} 1$ (enero-junio), 2004.

Malagón Pinzón, Miguel Alejandro. "La Revolución Francesa y el derecho administrativo francés. La invención de la teoría del acto político o de gobierno y su ausencia de control judicial", Diálogos de saberes: investigaciones y ciencias sociales, n. ${ }^{\circ}$ 23, Universidad Libre, 2005.

MaldonAdo GÓmEZ, TOMÁS. "La noción de servicio público a partir de la concepción del Estado social de derecho", Revista Actualidad Jurídica, n. ${ }^{\circ}$ 1, Universidad del Norte. 2010.

Mommsem, TeOdoro. Compendio del derecho público romano. Buenos Aires: Impulso, 1942.

Montaña Plata, Alberto. El concepto de servicio público en el derecho administrativo, 2. ${ }^{\text {a }}$ ed., Bogotá: Universidad Externado de Colombia. 2008

Montaña Plata, Alberto. Fundamentos de derecho administrativo. Bogotá: Universidad Externado de Colombia. 2010.

MOREnO ORTIZ, LUIS JAVIER. "Revolución Francesa y administración contemporánea. Eduardo García de Enterría", recensión, Revista de la Academia Colombiana de Jurisprudencia, n. ${ }^{\circ} 317,2000$, pp. 165-178.

Murillo Ferrol, Francisco. "El régimen jurídico de la administración inglesa". Revista de Administración Pública n. ${ }^{\circ} 1$ (enero-abril). 1950, pp. 39-77. 
Nieto García, Alejandro. "Algunas precisiones sobre el concepto de policía", Revista de Administración Pública, Madrid: n. ${ }^{\circ}$ 81, 1976.

PANTOJa BAUZA, ROLANDO. El derecho administrativo: concepto, características, sistematización, prospección. Santiago de Chile: Jurídica de Chile. 1996.

Parejo Alonso, Luciano. El concepto del derecho administrativo, 2. ${ }^{\text {a }}$ ed., Bogotá: Universidad Externado de Colombia. 2016.

Penagos, Gustavo. Fundamentos del derecho administrativo: origen francés en el mundo. Bogotá: Librería del Profesional. 1993.

Penagos, Gustavo. "Origen del derecho administrativo en la más remota Antigüedad", Revista Educación y Desarrollo Social, vol. 4, n. ${ }^{\circ}$ 1, Universidad Militar Nueva Granada. 1993.

PENDÓn MELÉnDEZ, ESTHER. Régimen jurídico de la prestación de servicios públicos en Derecho Romano, Madrid: Dykinson, 2002.

Pimiento ECHeVerry, Julián. Derecho administrativo de bienes. Los bienes públicos: bistoria, clasificación, régimen jurídico, Bogotá: Universidad Externado de Colombia, 2015.

RinCÓN CÓRDOBA, JORGE IVÁN. Las generaciones de los derechos fundamentales y la acción de la administración pública. Bogotá: Universidad Externado de Colombia, 2004.

RobSon, William A. Justice and Administrative Law: A Study of the British Constitution. London: Greenwood Press. 1951.

RodríGUEZ RodríGUEZ, LibARDO. Derecho administrativo: general y colombiano. 19. ed., Bogotá: Temis. 2015.

RodríGUEZ RodríGUEZ, LiBARDO. "La explicación histórica del derecho administrativo", en Estudios en bomenaje a don Jorge Fernández Ruiz. Derecho administrativo. México D.F: Universidad Nacional Autónoma de México, 2005.

SÁNCHEZ GONZÁLEZ, JOSÉ J. La administración pública como ciencia: su objeto y su estudio. México D.F.: Instituto de Administración Pública del Estado de México y Plaza y Valdés. 2001.

Soto Kloss, EduARdo. "Existe un derecho administrativo inglés?", Revista de Administración Pública n. ${ }^{\circ} 70$ (enero-abril). Madrid. 1973, pp. 113-184.

Von Justi, Juan E. Ciencia del Estado. México D.F.: Instituto de Administración Pública del Estado de México. 1996. 